\title{
Anti-proliferative effect of estrogen in breast cancer cells that re-express $E R \alpha$ is mediated by aberrant regulation of cell cycle genes
}

\author{
J G Moggs, T C Murphy, F L Lim, D J Moore, R Stuckey, K Antrobus, I Kimber and \\ G Orphanides
}

Syngenta CTL, Alderley Park, Cheshire SK10 4TJ, UK

(Requests for offprints should be addressed to J G Moggs; Email: jonathan.moggs@syngenta.com)

\begin{abstract}
Estrogen receptor (ER)-negative breast carcinomas do not respond to hormone therapy, making their effective treatment very difficult. The re-expression of ER $\alpha$ in ER-negative MDA-MB-231 breast cancer cells has been used as a model system, in which hormone-dependent responses can be restored. Paradoxically, in contrast to the mitogenic activity of $17 \beta$-estradiol (E2) in ER-positive breast cancer cells, E2 suppresses proliferation in ER-negative breast cancer cells in which $\mathrm{ER} \alpha$ has been re-expressed. We have used global gene expression profiling to investigate the mechanism by which E2 suppresses proliferation in MDA-MB-231 cells that express ER $\alpha$ through adenoviral infection. We show that a number of genes known to promote cell proliferation and survival are repressed by E2 in these cells. These include genes encoding the anti-apoptosis factor SURVIVIN, positive cell cycle regulators (CDC2, CYCLIN B1, CYCLIN B2, CYCLIN G1, CHK1, BUB3, STK6, SKB1, CSE1 L) and chromosome replication proteins (MCM2, MCM3, FEN1, RRM2, TOP2A, RFC1). In parallel, E2-induced the expression of the negative cell cycle regulators KIP2 and QUIESCIN Q6, and the tumour-suppressor genes E-CADHERIN and NBL1. Strikingly, the expression of several of these genes is regulated in the opposite direction by E2 compared with their regulation in ER-positive MCF-7 cells. Together, these data suggest a mechanism for the E2-dependent suppression of proliferation in ER-negative breast cancer cells into which $\mathrm{ER} \alpha$ has been reintroduced.
\end{abstract}

Journal of Molecular Endocrinology (2005) 34, 535-551

\section{Introduction}

Estrogens are important regulators of growth and differentiation in the normal mammary gland and participate in the development and progression of breast cancer (Pike et al. 1993). The mitogenic effects of estrogens on breast epithelial cells are mediated, at least in part, via the altered expression of genes involved in cell cycle regulation (Prall et al. 1997). Transcriptional regulation of estrogen-responsive genes is mediated by two members of the nuclear receptor superfamily, estrogen receptor (ER) $\alpha$ and ER $\beta$. These ERs function as ligand-activated transcription factors that recruit a variety of coregulator proteins to activate or repress the expression of estrogen-responsive genes (Moggs \& Orphanides 2001, Hall et al. 2001, McKenna and O’Malley 2002, Tremblay and Giguere 2002).

ER antagonists are used widely as therapeutic agents in the treatment of ER-positive breast cancers (Vogel 2003). In contrast, ER-negative breast cancers cannot be controlled by hormone therapy, making their effective treatment very difficult. This led to the suggestion that re-introducing ER into these cells would allow them to be controlled using anti-estrogen therapies. However, paradoxically, the reintroduction of ER $\alpha$ into ERnegative breast cancer cells results in the suppression of proliferation by 17ß-estradiol (E2) (Garcia et al. 1992, Levenson and Jordan 1994). The mechanism underlying this anti-proliferative effect of E2 in these cells is not known.

We have used global gene expression profiling to identify the molecular pathways through which estrogens suppress proliferation in ER-negative MDA-MB231 breast cancer cells that re-express ER $\alpha$. Our data reveal that, in these cells, E2 regulates the expression of a number of genes involved in cell proliferation and survival that have been previously associated with mitogenic stimulation by estrogens. However, strikingly, many of these genes are regulated in the opposite direction compared with their response in ER-positive MCF-7 breast cancer cells exposed to estrogens. Identification of the molecular networks associated with the suppression of proliferation in ER-negative breast cancer cells may allow the development of new strategies to control the growth of ER-negative breast tumours. 


\section{Materials and methods}

\section{Cell culture}

MDA-MB-231 cells were cultured routinely at $37{ }^{\circ} \mathrm{C}$ in humidified chambers at 5\% CO2 in Minimal Essential Media (MEM) supplemented with non-essential amino acids, $2 \mathrm{mM}$ glutamine, Penicillin, Streptomycin and 5\% charcoal-dextran-treated fetal calf serum. HEK293 cells were cultured as described in $\mathrm{He}$ et al. (1998). MCF-7 cells were maintained at $37^{\circ} \mathrm{C}$ in humidified chambers at 5\% CO2 in RPMI 1640 media containing phenol red, $2 \mathrm{mM}$ glutamine, Penicillin, Streptomycin and 10\% heat-inactivated fetal bovine serum. Prior to dosing with vehicle control (ethanol) or E2 (Sigma), MCF-7 cells were incubated for 4 days in RPMI 1640 media without phenol red and containing $2 \mathrm{mM}$ glutamine, Penicillin, Streptomycin and 5\% charcoal-dextran-treated fetal bovine serum.

\section{Adenoviral system used to express ER $\alpha$ in human MDA-MB-231 cells}

Full-length human ER $\alpha$ (1-595; Green et al. 1986) cDNA was cloned into the shuttle vector pAdTrackcytomegalovirus (CMV). The resulting construct was linearised and cotransformed into E. coli BJ5183 cells, together with an adenoviral backbone plasmid, pAdEasy-1 (He et al. 1998, see also Murphy \& Orphanides 2002). Selected recombinants were analysed by restriction endonuclease digestion. Finally, recombinant plasmids encoding ER $\alpha$ were linearised and transfected into an adenovirus packaging cell line, HEK 293, in order to generate recombinant adenovirus that expresses ER $\alpha$ (Ad-ER $\alpha$ ). A control recombinant adenovirus construct containing the $E$. coli $\beta$-galactosidase gene (Ad-LacZ) was constructured in a similar manner. Recombinant adenovirus was harvested from HEK293 cells using Arklone extraction, purified by ultracentrifugation through a caesium chloride gradient and dialysed in a Slide-a-lyser cassette (Perbio Science, Cramlington, Northumbria, UK). The purified adenovirus was aliquoted and stored at $-80^{\circ} \mathrm{C}$. Each virus stock was titered in MDA-MB-231 cells, to determine the multiplicity of infection (MOI). For analysis of E2-dependent transcriptional responses, MDA-MB-231 cells were transfected with either Ad-LacZ or Ad-ER $\alpha$ at a MOI of 2500. Since both Ad-LacZ and Ad-ER $\alpha$ were engineered to co-express the green fluorescent protein (GFP), infection levels could be quantified by monitoring the expression of the GFP using fluorescent microscopy $(\%$ Infectivity $=$ GFP cells $/$ total cells $\times 100)$. Twelve hours after the initial infection, transfected MDA-MB231 cells were photographed using both light and fluorescent microscopy, to determine the \% of GFP-expressing cells. Both Ad-LacZ and Ad-ER $\alpha$ reproducibly gave between 90 and 100\% infectivity of
MDA-MB-231 cells under these conditions. Expression of ER $\alpha$ in cells transfected with Ad-ER $\alpha$ was confirmed by Northern blot analysis (Sambrook et al. 1989) using $1 \%$ denaturing agarose gels containing $10 \mu \mathrm{g}$ total RNA per lane and a $417 \mathrm{bp}{ }^{32} \mathrm{P}$-labelled probe generated by PGR of the ER $\alpha$ cDNA (forward: 5'-ATAGGAAA AGACGGAAGAGGAG-'3; reverse: 5'-CGAGACGA GACCAATCATCA-`3).

\section{Reporter assay for ER-mediated transcription in MDA-MB-231 cells infected with adenovirus encoding ER $\alpha$}

MDA-MB-231 cells infected for $24 \mathrm{~h}$ with adenovirus $(\mathrm{MOI}=2500)$ encoding either $\beta$-galactosidase (control; Ad-LacZ) or ER $\alpha$ (Ad-ER $\alpha$ ) were co-transfected with a luciferase reporter construct that contained two copies of the vitellogenin estrogen response element (ERE) and also with a CMV-phRenilla plasmid (Promega), to measure transfection efficiency. After $24 \mathrm{~h}$, cells were treated with $0.01 \%$ ethanol, as a control, or E2 in fresh medium at the concentrations indicated. Cells were incubated for a further $24 \mathrm{~h}$ before harvesting for lysis and luciferase assays using the Dual-luciferase assay system (Promega). Results are expressed in terms of relative luciferase activity after normalisation for renilla luciferase activity \pm S.D.

\section{RT-PCR analysis of the endogenous estrogen-responsive gene pS2 in MDA-MB-231 cells infected with adenovirus encoding ERo}

Cells infected for $24 \mathrm{~h}$ with adenovirus $(\mathrm{MOI}=2500)$ encoding $\beta$-galactosidase (control; Ad-LacZ) or ER $\alpha$ (Ad-ER $\alpha$ ) were treated for 24,30 and $50 \mathrm{~h}$ with $0.01 \%$ ethanol, as a control, or $10^{-8} \mathrm{M}$ E2. Total RNA was isolated using Trizol reagent (Life Technologies) and purified according to the manufacturer's instructions. DNA-free RNA was prepared using a DNA-free kit (Ambion, Huntingdon, Cambs, UK) according to the manufacturer's instructions. DNase-treated RNA ( $1 \mu \mathrm{g})$ was reverse transcribed with oligo-dT using the Superscript II kit (Invitrogen) according to the manufacturer's instructions. PCR analysis of pS2 gene expression was performed using the oligonucleotide primers 5'-TGACTCGGGGTCGCGT TTGGAG-'3 and 5'-GTGAGCCGAGGCACAGCTG CAG-'3. The $\beta$-actin gene (5'-ACGATGGATGATG ATATCGG-'3 and 5'-ACATGGCTGGGGTGTTG AAG-'3) was used as a control.

\section{Cell proliferation assay}

Cells were maintained in MEM containing 5\% CDFCS and were seeded at 5000 cells/well in 24-well dishes in the same media. After overnight infection with Ad-LacZ 
Table 1 Taqman Gene expression assays used for quantitative real-time PCR

\begin{tabular}{|c|c|c|c|c|c|}
\hline & $\begin{array}{l}\text { Affymetrix } \\
\text { probe set }\end{array}$ & $\begin{array}{l}\text { Taqman gene } \\
\text { expression assay }\end{array}$ & $\begin{array}{l}\text { GenBank accession } \\
\text { number }\end{array}$ & $\begin{array}{l}\text { Exon } \\
\text { location }\end{array}$ & $\begin{array}{l}\text { Central } \\
\text { nucleotide } \\
\text { location }\end{array}$ \\
\hline \multicolumn{6}{|l|}{ Gene symbol } \\
\hline MCM2 & 202107_s_at & Hs00170472_m1 & NM_004526 & $2 / 3$ & 299 \\
\hline МСM3 & 201555_at & Hs00172459_m1 & NM_002388 & $12 / 13$ & 1938 \\
\hline MCM7 & 201112_s_at & Hs00428518_m1 & NM_182776 & $9 / 10$ & 1794 \\
\hline CSE1L & 202870_s_at & Hs00169158_m1 & NM_001316 & $14 / 15$ & 1614 \\
\hline CDC2 & 210559_s_at & Hs00176469_m1 & NM_001786 & 12 & 107 \\
\hline CDC20 & 203213_at & Hs00415851_g1 & NM_001255 & 12 & 59 \\
\hline BUB1 & 209642_at & Hs00177821_m1 & NM_004336 & $1 / 2$ & 73 \\
\hline BIRC5 & 202095_at & Hs00153353_m1 & NM_001168 & $3 / 4$ & 393 \\
\hline FEN1 & 204768_s_at & Hs00748727_s1 & NM_004111 & 2 & 643 \\
\hline FOSL1 & 204420_at & Hs00759776_s1 & NM_005438 & 4 & 1103 \\
\hline RPLP0/36B4 & 201033_x_at & Hs99999902_m1 & NM_001002 & - & 267 \\
\hline
\end{tabular}

or Ad-ER $\alpha(\mathrm{MOI}=2500)$, the medium was removed and replaced with fresh medium containing either $0.01 \%$ ethanol, as a control, or $10^{-8}$ M E2 for $24 \mathrm{~h}$. Cells were then incubated with $1 \mu \mathrm{Ci}$ [methyl${ }^{3} \mathrm{H}$ ] thymidine at $37^{\circ} \mathrm{C}$ for $4 \mathrm{~h}$. Plates were sequentially washed and fixed with ice cold PBS, 10\% TCA, MeOH and the incorporated label was recovered by incubation of the wells in $0.5 \mathrm{M} \mathrm{NaOH}$ for $30 \mathrm{~min}$ at $37^{\circ} \mathrm{C}$. Lysates were transferred to vials containing Optiphase 'hi-safe' 3 scintillation cocktail (PerkinElmer Life Sciences, Beaconsfield, Bucks, UK) and $\left[{ }^{3} \mathrm{H}\right]$ thymidine incorporation (c.p.m.) was determined in a scintillation counter.

\section{Affymetrix GeneChip transcript profiling and data analysis for MDA-MB-231 cells infected with adenovirus encoding ER $\alpha$}

Cells infected for $24 \mathrm{~h}$ with adenovirus $(\mathrm{MOI}=2500)$ encoding $\beta$-galactosidase (control; Ad-LacZ) or ER $\alpha$ (Ad-ER $\alpha$ ) were treated for $48 \mathrm{~h}$ with $0.01 \%$ ethanol, as a control, or $10^{-8} \mathrm{M}$ E2. Total RNA was isolated using Trizol reagent (Life Technologies) and purified according to the manufacturer's instructions. Biotin-Labeled complementary RNAs were synthesized using the Bioarray HighYield RNA Transcript Labeling Kit (Affymetrix, High Wycombe, Bucks, UK) from $5 \mu \mathrm{g}$ total RNA and hybridised to Affymetrix human U133A GeneChips as described in the Affymetrix GeneChip Technical Manual. Microarrays were then scanned and the intensities were averaged using Microarray Analysis Suite 5.0 (Affymetrix). The mean signal intensity of each array was globally normalized to 500. Affymetrix pivot files were imported into GeneSpring 6.0 (Silicon Genetics, Redwood City, CA, USA) and normalised to the 50th percentile of each GeneChip and to the median of each gene. Normalised data was filtered to exclude genes that lack a present flag or a raw signal strength $>500$ in any of the treatment groups. The three independent biological replicates data sets for MDAMB-231 cells infected Ad-LacZ $( \pm \mathrm{E} 2)$ or Ad-ER $\alpha$ $( \pm \mathrm{E} 2)$ were initially filtered using a one-sample Student's $t$-test $(P<0.05)$ to identify statistically differentially expressed genes within each treatment group. The resulting 574 genes were subsequently analysed using a one-way ANOVA test with the following conditions: parametric test assuming equal variance, Benjamini and Hochberg false discovery rate $<0.01$ (Benjamini \& Hochberg 1995), Tukey post-hoc testing (see http:// www.silicongenetics.com for further details). Using these criteria, less than $1 \%$ of the 88 genes selected by ANOVA can be expected to be significant by chance. Genes with similar expression profiles were grouped together using hierarchical clustering (Pearson correlation). Gene names used in this manuscript were derived by homology searching of nucleotide sequence databases (BLASTn) using Affymetrix probe target sequences and the NetAffx (Liu et al. 2003) database. All genes described in the figures and text showed statistically significant alterations in expression in all three replicate studies. MIAME (Minimum Information About a Microarray Experiment)-compliant microarray data for the three independent replicate studies were submitted to the Gene Expression Omnibus (GEO) database (GEO 2004).

\section{Quantitative real-time PCR analysis of gene expression}

DNA-free RNA was prepared using 'DNA-free' (Ambion) according to the manufacturer's instructions. DNase-treated RNA $(0.7 \mu \mathrm{g})$ was reverse transcribed with random hexamers using Superscript III kit (Invitrogen) according to the manufacturer's instructions. All quantitative real-time PGR reactions were carried out using an ABI Prism 7700 sequence detection system (Applied Biosystems, Warrington, Chester, UK). 
The thermal cycler conditions were, $2 \mathrm{~min}$ at $50{ }^{\circ} \mathrm{C}$ and $10 \mathrm{~min}$ at $95^{\circ} \mathrm{C}$ followed by 15 seconds at $95^{\circ} \mathrm{C}$ (denaturation) and $1 \mathrm{~min}$ at $60^{\circ} \mathrm{C}$ (anneal-extension) for 40 cycles. The total volume for each reaction was $20 \mu \mathrm{l}$ comprising $9 \mu \mathrm{l}$ diluted cDNA $(0.5 \mathrm{ng} / \mu \mathrm{l}), \quad 10 \mu \mathrm{l}$ Taqman Universal Master mix and $1 \mu$ l Taqman gene expression assay (Applied Biosystems). Each Taqman gene expression assay contains forward primer, reverse primer and Taqman MGB probe (primer locations and corresponding gene accession numbers are shown in Table 1). Each RNA sample was assayed in triplicate and the mean $\mathrm{Ct}$ value was calculated. The fold change was determined using the $\Delta \Delta \mathrm{Ct}$ method. All genes were normalised to the control gene RPLP0/36B4 (Accession number: NM_001002; Laborda 1991).

\section{Results}

\section{Reintroduction of functional ER $\alpha$ into ER-negative MDA-MB-231 breast cancer cells by adenoviral transfection}

We used a recombinant adenoviral delivery system to examine the molecular mechanisms through which the reintroduction of ER $\alpha$ into ER-negative MDA-MB-231 breast cancer cells confers E2-dependent suppression of proliferation. (He et al. 1998, Fig. 1A). Recombinant adenoviruses were engineered to co-express the fulllength human ER $\alpha$ cDNA (amino acids 1-595; Green et al. 1986) and GFP, as described in the Materials and methods (Ad-ER $\alpha$ ). Recombinant adenoviruses containing the $E$. coli $L A C Z$ gene in place of the human ER $\alpha$ gene were used as a control (Ad-LacZ). Quantification of infection levels in MDA-MB-231 cells by fluorescent microscopy revealed that GFP was expressed in $>90 \%$ of cells after infection (Fig. 1B). The expression of a transcript corresponding to the transfected human ER $\alpha$ cDNA was confirmed by Northern blotting (Fig. 1G). Quantitative real-time PCR analysis of $\mathrm{ER} \alpha$ gene expression levels (data not shown) revealed that the reintroduction of ER $\alpha$ into ER-negative MDA-MB-231 breast cancer cells by adenoviral transfection results in higher levels ( $\sim 5$-fold) of ER $\alpha$ expression than those found in MCF-7 breast cancer cells, consistent with previous studies (Lazennec \& Katzenellenbogen 1999).

To confirm that ER $\alpha$ re-expression in MDA-MB-231 cells was functional, we used a reporter-based transfection assay that measures the ability of ligand-activated ERs to regulate transcription via a consensus multimerised ERE present on a transiently transfected plasmid. In cells infected with Ad-ER $\alpha$, but not in cells infected with Ad-LacZ, the addition of E2 $\left(10^{-8} \mathrm{M}\right.$ and $\left.10^{-7} \mathrm{M}\right)$ increased reporter gene expression $(4 \cdot 8-$ and $3 \cdot 3$-fold respectively; Fig. 2A), demonstrating that adenoviral infection resulted in the expression of transcriptionally active ER $\alpha$. We next examined the ability of

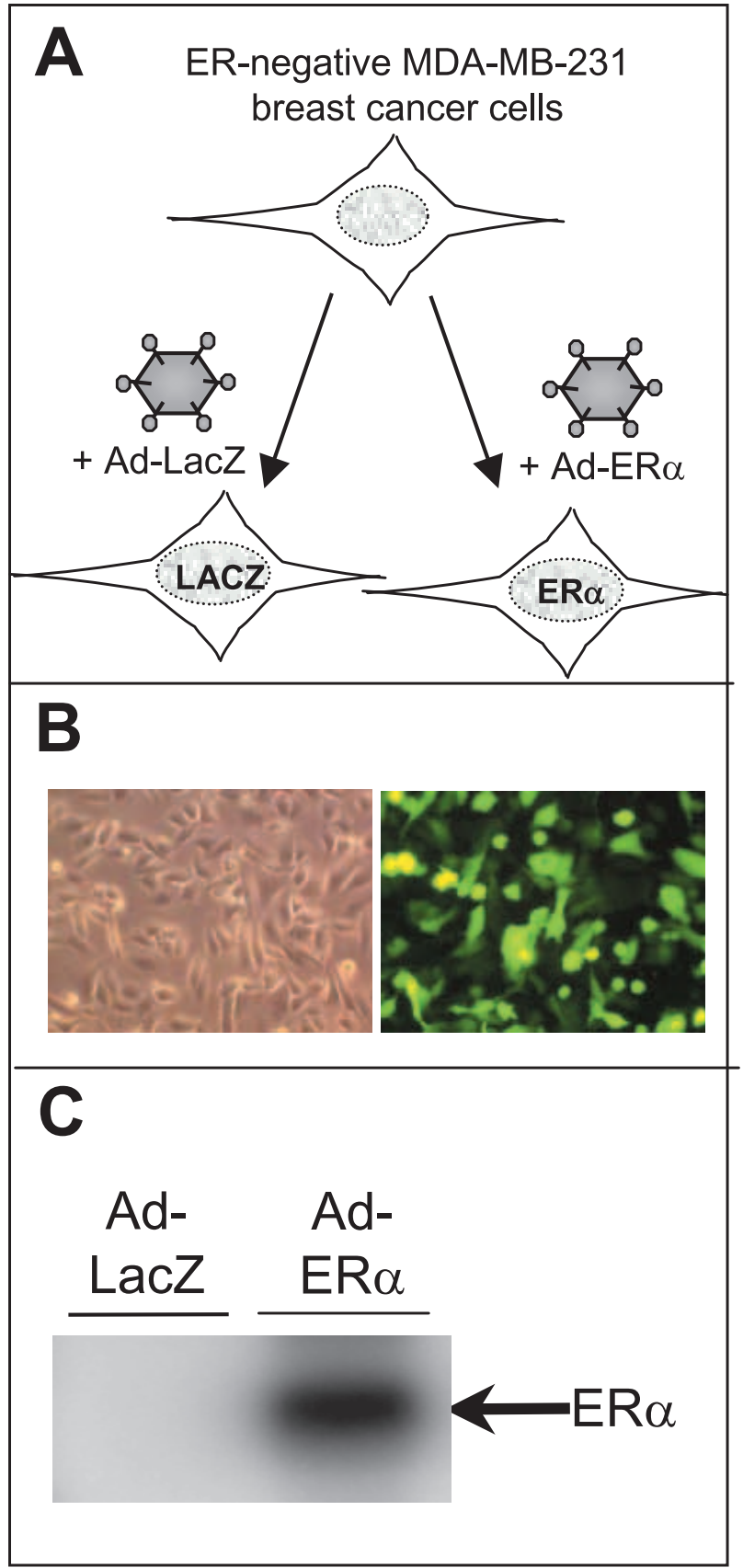

Figure 1 Reintroduction of ER $\alpha$ into ER-negative MDA-MB-231 breast cancer cells. (A) Recombinant adenovirus engineered to co-express both GFP and human $\mathrm{ER} \alpha(\mathrm{Ad}-\mathrm{ER} \alpha)$ was used to infect MDA-MB-231 cells. Recombinant adenovirus containing the $E$. coli $L A C Z$ gene in place of $E R \alpha(A d-L a c Z)$ was used as a control. (B) MDA-MB-231 cell infection efficiencies of greater than $90 \%$ were measured routinely using the adenovirus constructs at a MOI of 2500. Left panel: light microscopy of MDA-MB-231 cells $24 \mathrm{hr}$ after infection with Ad-ER $\alpha$. The efficiency of viral infection was determined by measuring the proportion of cells that exhibit GFP fluorescence (right panel). (C) Northern blot analysis of ER $\alpha$ expression $24 \mathrm{~h}$ after Ad-LacZ (lane 1) or Ad-ER $\alpha$ (lane 2) infection of MDA-MB-231 cells. 
adenoviral-encoded ER $\alpha$ to regulate endogenous (i.e. chromosomal) genes. For this purpose, we selected the classical estrogen responsive gene, pS2 (also known as TFF1; Davidson et al. 1986), which contains a consensus ERE in its promoter region and is regulated directly by ERs (Berry et al. 1989). Gells infected with Ad-LacZ or Ad-ER $\alpha$ were treated with $10^{-8} \mathrm{M} \mathrm{E2}$ or vehicle (ethanol) for 24, 30 or $50 \mathrm{~h}$ prior to RT-PCR analysis of pS2 gene expression. As expected, pS2 gene expression was induced by E2 in cells expressing ER $\alpha$ (Fig. 2B, lanes 7 to 12), but not in control cells (Fig. 2B, lanes 1 to 6). Therefore, the adenovirus-encoded ER $\alpha$ is capable of activating an endogenous chromosomal gene in the presence of E2.

(A)

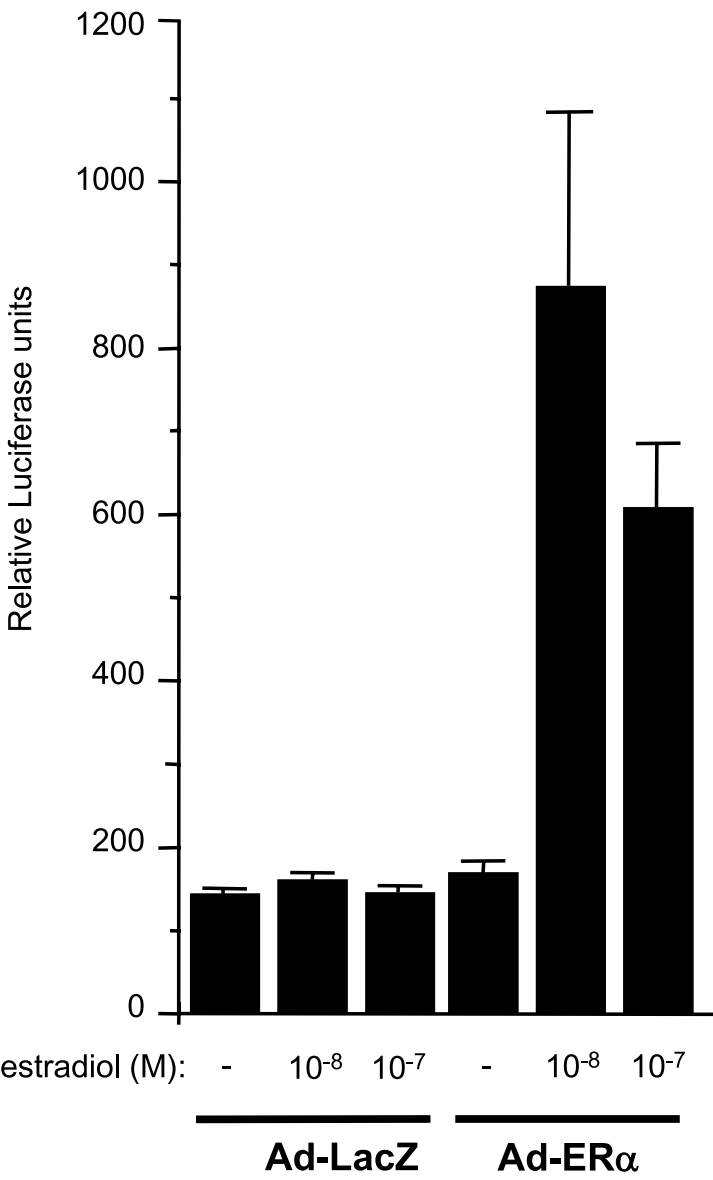

(B)

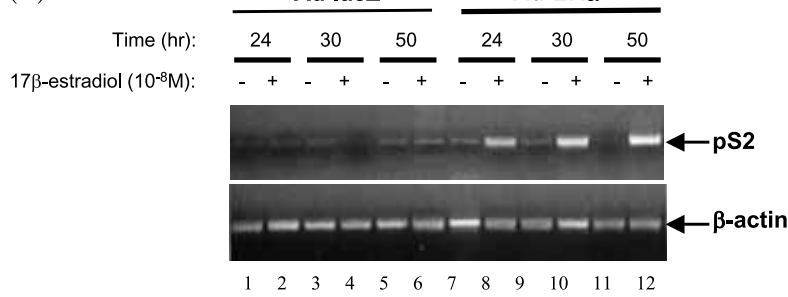

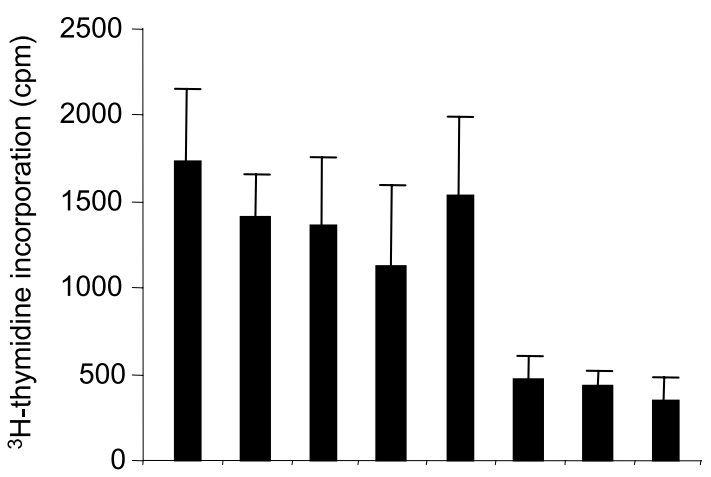

$17 \beta$-estradiol (M): \begin{tabular}{lll}
$10^{-9} 10^{-8} 10^{-7}$ \\
\hline
\end{tabular}

Ad-LacZ
- $10^{-9} 10^{-8} 10^{-7}$
Figure 3 E2 inhibits proliferation in MDA-MB-231 breast cancer cells that re-express $\mathrm{ER} \alpha$ after transfection with Ad-ER $\alpha$. MDA-MB-231 cells were infected with either Ad-LacZ or $\mathrm{Ad}-\mathrm{ER} \alpha$. The cells were then treated with control vehicle $(0.01 \%$ ethanol) or E2 at the concentrations indicated for $24 \mathrm{~h}$. Proliferation was measured by [methyl- ${ }^{3} \mathrm{H}$ ] thymidine incorporation. Values are the mean+S.D. of three determinations. Similar results were obtained in two independent experiments.

We next examined the effect of adenoviral transfection of ER $\alpha$ on cell proliferation. The re-expression of human ER $\alpha$ in MDA-MB-231 breast cancer cells restores hormone responsiveness, but leads to the inhibition of proliferation by E2 (Garcia et al., 1992, Levenson and Jordan 1994, Lazennec and Katzenellenbogen 1999). Consistent with these observations, E2 caused a 3-fold decrease in proliferation in MDA-MB231 cells that re-express ER $\alpha$ (Fig. 3).

We conclude that adenoviral transfection of ER $\alpha$ into the ER-negative MDA-MB-231 breast cancer cell line confers both transcriptional and anti-proliferative responses to E2. Therefore, this model system is suitable for investigating the mechanism by which E2 suppresses proliferation in ER-negative cells that re-express ER $\alpha$.

Figure 2 MDA-MB-231 cells infected with adenovirus encoding $E R \alpha$ contain transcriptionally active ERs. (A) Cells were infected with adenovirus encoding $\beta$-galactosidase (Ad-LacZ control) or ER $\alpha(\mathrm{Ad}-\mathrm{ER} \alpha)$ and were co-transfected with a luciferase reporter construct, that contained two copies of the vitellogenin ERE, and with the CMV-phRenilla plasmid (to measure transfection efficiency). After $24 \mathrm{~h}$, cells were treated with $0.01 \%$ ethanol, as a control, or estradiol at the concentrations indicated. Results are expressed as relative luciferase activities after normalisation for Renilla luciferase activity +S.D. $(n=6)$. (B) MDA-MB-231 cells infected with $A d-L a c Z$ or Ad-ER $\alpha$ were treated with vehicle (ethanol) or E2 $\left(10^{-8} \mathrm{M}\right)$ for the times indicated and the expression of the endogenous pS2 gene was analysed by RT-PCR. The $\beta$-actin gene was used as a control. 


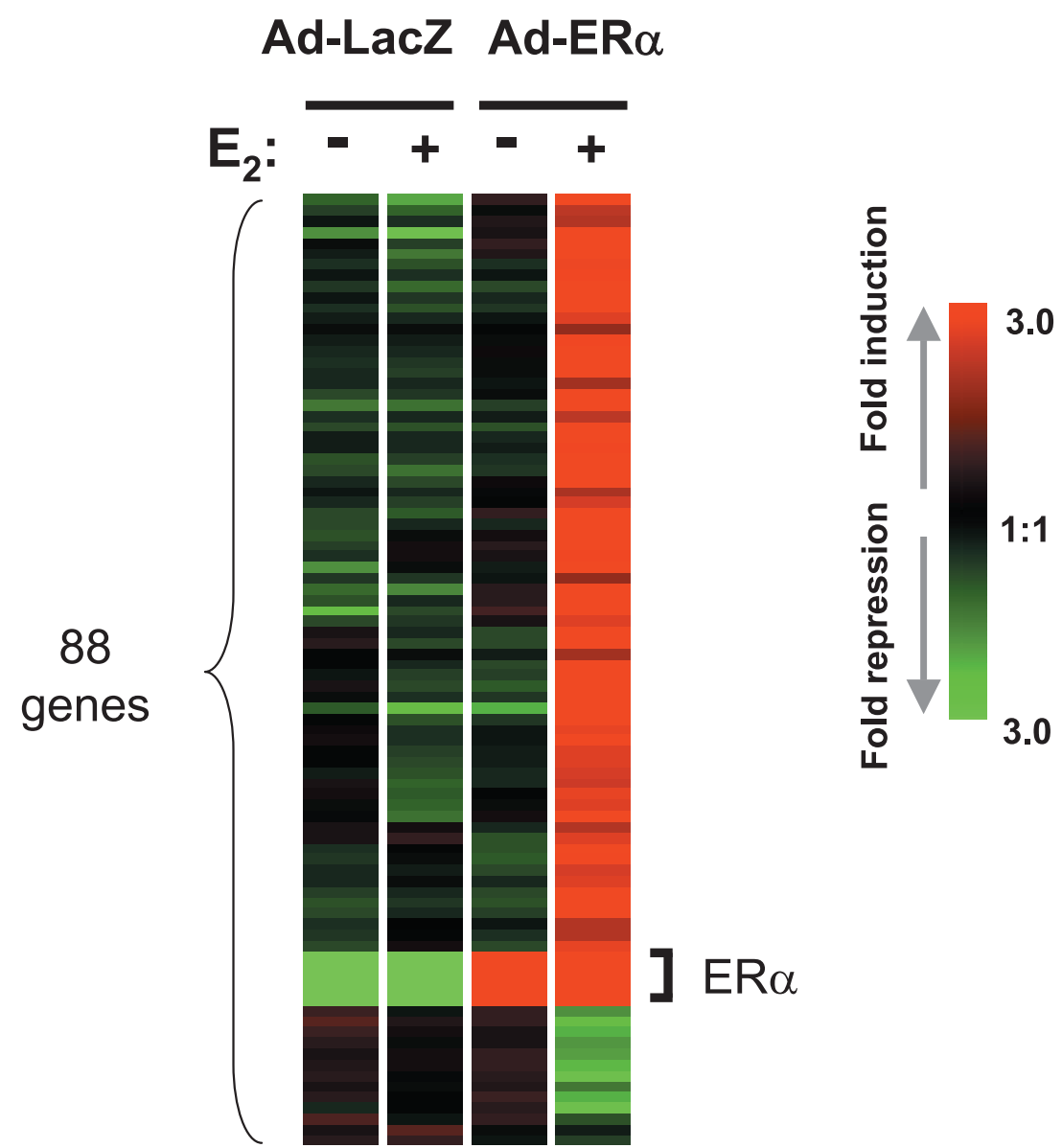

Figure 4 Microarray analysis of estrogen-responsive genes in MDA-MD-231 breast cancer cells transfected with Ad-LacZ or Ad-ER $\alpha$. Statistical analysis of Affymetrix HG-U133A GeneChip data was performed on three independent biological replicate studies of MDA-MB-231 cells infected with either Ad-LacZ or Ad-ER $\alpha$ prior to $48 \mathrm{~h}$ incubation with either vehicle control $\left(0.01 \%\right.$ ethanol) or $10^{-8} \mathrm{M}$ E2. Differentially expressed genes within each treatment group were identified using a one sample Student's $t$-test $(P<0.05)$. The resulting 547 genes were subsequently filtered using a stringent one-way ANOVA test combined with Benjamini and Hochberg multiple testing correction (false discovery rate $<0.01$; Benjamini \& Hochberg 1995). Using these criteria, less than $1 \%$ of the 88 genes shown can be expected to be significant by chance. Genes with similar expression profiles were grouped together using hierarchical clustering (Pearson correlation) and the resulting gene tree is shown. The magnitude of fold-induction or -repression for each gene (relative to the median of its expression across all experimental samples) is indicated by the colour bar. Data shown are based on three replicate studies. Quantitative data for the magnitude of each gene expression change, together with gene descriptions and Affymetrix probe set IDs are shown in Table 2.

\section{Changes in gene expression associated with estrogen-induced suppression of proliferation in ER-negative MDA-MB-231 breast cancer cells that re-express ERa}

\section{Statistical analysis of genes regulated by E2}

We used microarray gene expression profiling to obtain a holistic view of the endogenous transcriptional targets of ER $\alpha$ in our model system. The expression of 22483 genes in each of four treatment groups (Ad-LacZ, Ad-LacZ+E2, Ad-ER $\alpha$ and Ad-ER $\alpha+E 2)$ was measured using the Affymetrix human GeneChip U133A, and the resulting data were subjected to rigorous statistical analyses (Materials and methods). 574 gene probe sets were selected as being significantly $(P<0 \cdot 05)$ under- or over-expressed in one or more of the 4 treatment groups using a Student's $t$-test, based on data from three independent biological replicates. A stringent ANOVA 
Table 2 Genes regulated by E2 in MDA-MB-231 cells that re-express ER $\alpha$

\section{Gene name}

Affymetrix prot
201531 at
212442 _sat
201339_s_at
218002 s_at
210517 s_at
209304_x_at
210059_s_at
211168_s_at
219480_at
205016_at
203058_s_at
205206_at
40829_at
218322 _s_at
204158 s_at
200884 at
218532 a at
205105 at
201720 s_at

205899_at 31637_s_at

203060_s_at

201721_s_at

218692_at 205009_at 210357_s_at 211429_s_at

220486_x_at 204326_x_at 202833_s_at

218749_s_at

203059_s_at

213004 at 217744_s_at 207935 s at 212216_at 203071_at 202267_at 201131_s_at zinc finger protein 36

LAG1 longevity assurance

homolog 6

sterol carrier protein 2

chemokine ligand 14

A kinase anchor protein 12

growth arrest and DNA

damage-inducible, beta

mitogen-activated protein

kinase 13

regulator of nonsense

transcripts 1

snail homolog 1

transforming growth factor,

alpha

3'-phosphoadenosine

5'-phosphosulfate synthase 2

Kallmann syndrome 1

sequence

WD and tetratricopeptide

repeats 1

acyl-CoA synthetase long-chain

family member 5

T-cell, immune regulator 1 ,

ATPase, $\mathrm{H}+$ transporting

creatine kinase

hypothetical protein FLJ20152

mannosidase, alpha 2A1

Lysosomal-associated

multispanning membrane

protein-5

cyclin A1

nuclear receptor subfamily 1 ,

group $D$, member 1

3'-phosphoadenosine

5'-phosphosulfate synthase 2

Lysosomal-associated

multispanning membrane

protein-5

hypothetical protein FLJ20366

trefoil factor 1

spermine oxidase

serine protease inhibitor, clade

A, member 1

hypothetical protein FLJ22679

metallothionein $1 \mathrm{X}$

serine protease inhibitor, clade

$\mathrm{A}$, member 1

solute carrier family 24 ,

member 6

3'-phosphoadenosine

5 '-phosphosulfate synthase 2

angiopoietin-like 2

TP53 apoptosis effector

keratin 13

putative amino acid transporter

semaphorin $3 \mathrm{~B}$

laminin, gamma 2

E-cadherin

\section{Biological pathway/ process}

mRNA catabolism

LASS6

SCP2

CXCL14

AKAP12

GADD45B

MAPK13

RENT1

SNAI1

TGFA

PAPSS2

KAL1

WDTC1

ACSL5

TCIRG1

CKB

FLJ20152

MAN2A1

LAPTM5

CCNA1

NR1D1

PAPSS2

LAPTM5

FLJ20366

TFF1

SMOX

SERPINA1

FLJ22679

MT1X

SERPINA1

SLC24A6

PAPSS2

ANGPTL2

PERP

KRT13

KIAA0436

SEMA3B

LAMC2

$\mathrm{CDH} 1$

steroid biosynthesis

cell cycle

regulation/apoptosis

regulation of

translation/signaling

mRNA catabolism

transcription

regulation of cell

cycle/signaling

cell adhesion

fatty acid metabolism

defense

response/proliferation

regulation of cell cycle regulator

electron transport

acute-phase response

response to metal ion

acute-phase response

development

apoptosis

cytoskeleton

signaling

cell adhesion
Ratio of gene expression E2:AO (mean \pm S.D.)

$3 \cdot 8 \pm 1 \cdot 9$

$2 \cdot 2 \pm 0 \cdot 6$

$1 \cdot 9 \pm 0.5$

$30 \cdot 3 \pm 10 \cdot 7$

$3 \cdot 2 \pm 0 \cdot 6$

$4 \cdot 1 \pm 1 \cdot 5$

$3 \cdot 1 \pm 1 \cdot 3$

$3 \cdot 2 \pm 1 \cdot 6$

nucleic acid metabolism

$12 \cdot 6 \pm 6 \cdot 3$

$4 \cdot 3 \pm 1 \cdot 0$

$8 \cdot 4 \pm 3 \cdot 8$

$2 \cdot 6 \pm 0 \cdot 7$

$1 \cdot 6 \pm 0 \cdot 3$

$2 \cdot 9 \pm 0 \cdot 8$

amino acid metabolism

carbohydrate metabolism

$5 \cdot 9 \pm 1 \cdot 8$

$5 \cdot 4 \pm 1 \cdot 7$

$10 \cdot 7 \pm 5 \cdot 5$

$1 \cdot 9 \pm 0 \cdot 4$

$3 \cdot 9 \pm 0 \cdot 8$

$5 \cdot 9 \pm 3 \cdot 1$

transcription/circadian rhythm

nucleic acid metabolism

$2 \cdot 2 \pm 0 \cdot 4$

$6 \cdot 9 \pm 1 \cdot 9$

$4 \cdot 3 \pm 1 \cdot 5$

$3 \cdot 0 \pm 0 \cdot 6$

cell growth/defense response

$22 \cdot 3 \pm 4 \cdot 9$

$4 \cdot 4 \pm 1 \cdot 2$

$8.5 \pm 1 \cdot 2$

$1 \cdot 9 \pm 0 \cdot 2$

$2 \cdot 3 \pm 0 \cdot 3$

$10 \cdot 9 \pm 0 \cdot 3$

$4 \cdot 2 \pm 1 \cdot 6$

nucleic acid metabolism

$8 \cdot 4 \pm 1 \cdot 7$

$6 \cdot 9 \pm 2 \cdot 3$

$2 \cdot 9 \pm 1 \cdot 2$

$16 \cdot 8 \pm 0 \cdot 4$

$1 \cdot 7 \pm 0 \cdot 3$

$7 \cdot 7 \pm 1 \cdot 9$

$4 \cdot 2 \pm 1 \cdot 3$

$35 \cdot 2 \pm 35 \cdot 4$ 
Table 2 Continued

\section{Gene name}

Affymetrix probe set
202950 at
216323 _x_at
203661_s_at
202053_s_at
204368_at
209035_at
204664_at

213308_at
214476_at
213001_at
217165_x_at
203585_at
210740_s_at
206461_x_at
205068_s_at
212057_at
202458_at
201858_s_at
219369_s_at
211474_s_at
213909_at

202756_s_at 219045_at

205148_s_at 202976_s_at

201349_at

221667_s_at 215189 at 210827_s_at 212135_s_at 210609_s_at

$217190 \times$ at 215552_s_at 211233_x_at 211234_x at 211235_s_at 218399_s_at 202870_s_at 211519_s_at 201897_s_at 210983_s_at crystallin, zeta

tubulin, alpha 2

tropomodulin 1

aldehyde dehydrogenase 3

family, member A2

solute carrier organic anion

transporter family, member 2A1

midkine

alkaline phosphatase

SH3 and multiple ankyrin

repeat domains 2

trefoil factor 2

angiopoietin-like 2

metallothionein $2 \mathrm{~A}$

zinc finger protein 185

inositol 1,3,4-triphosphate 5/6

kinase

metallothionein $1 \mathrm{H}$

Rho GTPase activating protein 26

KIAA0182 protein

serine protease 23

proteoglycan 1

OUT domain, ubiquitin

aldehyde binding 2

serine protease inhibitor, clade

$\mathrm{B}$, member 6

leucine rich repeat containing 15

glypican 1

ras homolog gene family,

member 5

chloride channel 4

Rho-related BTB domain

containing 3

solute carrier family 9 , isoform

3 regulator 1

heat shock protein 8

keratin 6

E74-like factor 3

ATPase, $\mathrm{Ca}^{2+}$ transporting

tumor protein p53 inducible

protein 3

estrogen receptor alpha

estrogen receptor alpha

estrogen receptor alpha

estrogen receptor alpha

estrogen receptor alpha

cell division cycle associated 4

cell division cycle 20 homolog

kinesin family member $2 \mathrm{C}$

CDC28 protein kinase subunit 1B

minichromosome maintenance deficient 7

\section{Biological pathway/ process}

CRYZ

TUBA2

TMOD1

ALDH3A2

SLCO2A1

MDK

ALPP

SHANK2

TFF2

ANGPTL2

MT2A

ZNF185

ITPK1

MT1H

ARHGAP26

KIAA0182

SPUVE

PRG1

OTUB2

SERPINB6

acute-phase response

LRRC15

GPC1

RHOF

CLCN4

RHOBTB3

SLC9A3R1

HSPB8

KRTHB6

ELF3

ATP2B4

TP53I3

ESR1

ESR1

ESR1

ESR1

ESR1

CDCA4

CDC20

KIF2C

CKS1B

MCM7

cytoskeleton

aldarate and fatty acid

metabolism

lipid transport

regulation of cell

cycle/signaling

glycerolipid

metabolism/folate

biosynthesis

signaling

defense response

development

signal transduction

response to metal ion

growth/cytoskeleton

proteolysis

development

ion transport

signaling/cytoskeleton

transcription

apoptosis

transcription/signaling

transcription/signaling

transcription/signaling

transcription/signaling

transcription/signaling

regulation of cell cycle

regulation of cell cycle

mitosis/proliferation

cell proliferation

DNA replication
Ratio of gene expression E2:AO (mean \pm S.D.)

$2 \cdot 4 \pm 0.5$

microtubule

$4 \cdot 0 \pm 1 \cdot 8$

$7 \cdot 5 \pm 2 \cdot 9$

$2 \cdot 0 \pm 0 \cdot 2$

$8 \cdot 9 \pm 0 \cdot 8$

$4 \cdot 1 \pm 1 \cdot 7$

copper ion homeostasis

$7 \cdot 9 \pm 4 \cdot 2$

$129 \cdot 1 \pm 86 \cdot 8$

$35 \cdot 1 \pm 20 \cdot 8$

$3.9 \pm 0.8$

$2 \cdot 8 \pm 0.5$

$3 \cdot 0 \pm 0 \cdot 6$

$2 \cdot 7 \pm 0.8$

$2 \cdot 8 \pm 1 \cdot 2$

$2 \cdot 6 \pm 0 \cdot 2$

$2 \cdot 6 \pm 1 \cdot 1$

$2 \cdot 6 \pm 0 \cdot 1$

$2 \cdot 5 \pm 0.5$

$4 \cdot 2 \pm 1 \cdot 5$

$2 \cdot 2 \pm 0 \cdot 4$

$3 \cdot 1 \pm 1 \cdot 0$

$4 \cdot 7 \pm 2 \cdot 2$

$4 \cdot 0 \pm 2 \cdot 1$

$3 \cdot 1 \pm 1 \cdot 3$

$2 \cdot 8 \pm 1 \cdot 3$

$7 \cdot 5 \pm 5 \cdot 0$

$7 \cdot 0 \pm 2 \cdot 5$

$11 \cdot 8 \pm 8 \cdot 5$

$2 \cdot 1 \pm 0 \cdot 4$

$2 \cdot 2 \pm 0.4$

$3 \cdot 2 \pm 0 \cdot 8$

$1.5 \pm 0.4$

$1 \cdot 3 \pm 0.4$

$1 \cdot 2 \pm 0.5$

$1.2 \pm 0.5$

$1 \cdot 2 \pm 0.4$

$0.6 \pm 0.09$

$0.5 \pm 0.1$

$0.5 \pm 0.1$

$0.6 \pm 0.1$ 


\section{Gene name}

Affymetrix probe set
202503_s_at
204420_at
208002_s_at
202095_s_at
204521_at
220155_s_at
208994_s_at
210006_at

KIAA0101 gene product FOS-like antigen 1 acyl-CoA hydrolase survivin

predicted protein clone 23733 bromodomain containing 9 peptidyl-prolyl isomerase $\mathrm{G}$ DKFZP564O243 protein

\section{Biological pathway/ process}

KIAA0101
FOSL1
BACH
BIRC5
HSU79724
BRD9
PPIG
DKFZP5640243

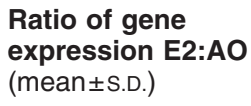

transcription/proliferation
lipid metabolism
cell cycle
regulation/apoptosis
protein folding/RNA splicing
aromatic compound
metabolism

$0.5 \pm 0.07$

$0.4 \pm 0.1$

$0.6 \pm 0.07$

$0.5 \pm 0.06$

$0.4 \pm 0.1$

$0.7 \pm 0.08$

$1.0 \pm 0.06$

$0.9 \pm 0.05$

Eighty-three genes demonstrated significantly induced or repressed expression after E2 stimulation of MDA-MB-231 cells that re-express ERa (based on ANOVA using Benjamini and Hochberg multiple testing correction (false positive discovery rate <0.01; Benjamini \& Hochberg 1995)). Mean gene expression ratios \pm S.D. (E2-treated relative to vehicle control; based on three independent biological replicate experiments) are shown together with Affymetrix GeneChip probe set, gene name, biological pathway/process (as of the NetAffx update on 23 June 2004). Two or more Affymetrix GeneChip probe sets for the same gene indicates that probe sets specific for independent regions of the same gene demonstrated estrogen-regulated expression.

test (Benjamini and Hochberg multi-testing correction, false positive rate $<0 \cdot 01$; Benjamini \& Hochberg 1995) was then applied, resulting in the identification of 88 gene probe sets showing differential expression between one or more of the 4 treatment groups (Fig. 4). Five of these gene probe sets represented the $\mathrm{ER} \alpha$ gene, confirming that this gene was re-expressed in MDA-MB231 cells infected with the $\mathrm{ER} \alpha$ adenoviral construct. None of the 88 gene probe sets were E2-responsive in MDA-MB-231 cells transfected with the control adenovirus construct (Ad-LacZ), consistent with the ER-negative status of this cell line. In contrast, 83 probe sets showed a transcriptional response to E2 in MDA-MB-231 cells transfected with Ad-ER $\alpha$. The magnitude of E2-dependent alterations in gene expression for the 83 gene probe sets, together with their gene ontology descriptions and functional classifications, are shown in Table 2. These genes include the classical E2-responsive gene pS2/TFF1 (Davidson et al. 1986, Berry et al. 1989) and TGFA, both of which have previously been observed to be up-regulated by E2 after adenoviral transfection of ER $\alpha$ into MDA-MB-231 cells (Lazennec \& Katzenellenbogen 1999).

\section{Gene ontology and promoter analysis of ERa-dependent estrogen-responsive genes.}

The molecular functions of the 83 E2-responsive genes we identified fall into a broad range of gene ontology classifications (Liu et al. 2003, Bard \& Rhee 2004), including cell cycle control, signalling, growth factors, transporters, defense responses and cell adhesion (Table 2), highlighting the diverse gene networks and metabolic and cell regulatory pathways through which E2 exerts its effects on breast cancer cells. Many of these genes have not previously been identified as being E2-responsive in breast cancer cells, and include genes whose function is unknown (e.g. FL720152, FLf20366, FLf22679; Table 1).

In order to gain more evidence that these genes were regulated directly by ER $\alpha$, we searched their regulatory regions for EREs, based on similarity to the consensus ERE sequence (Klinge 2001). In silico analysis of the sequences found $3000 \mathrm{bp}$ immediately upstream of the transcriptional start site of each of the 83 genes and revealed the presence of one or more candidate EREs (Table 3). This provides further evidence that the genes we have identified are regulated by $\mathrm{ER} \alpha$ directly. A number of these ERE motifs have also been identified independently in a recent genome-wide screen for ERE motifs in the human and mouse genomes (Bourdeau et al. 2004).

\section{Estrogen represses the expression of genes that promote cell proliferation and survival}

Several of the E2-responsive genes we have identified (e.g. MCM7, CDC20, CKSB1, SURVIVIN; Table 2) have been shown previously to be involved in the regulation of cell proliferation and survival. Among these genes is: (1) the MCM7 (minichromosome maintenance deficient 7) gene, encoding a DNA replication licensing factor that functions to limit a cell to a single round of replication per cell cycle (Blow \& Hodgson 2002); (2) the WD-repeat protein CDC20, essential for progression through mitosis (Vodermaier 2001); (3) the CKS1B gene, encoding a substrate-targeting subunit of the SCF ubiquitin ligase complex that regulates the entry into $\mathrm{S}$ 
Table 3 Identification of putative estrogen-response elements (EREs) in E2-responsive genes identified by microarray analysis of MDA-MD-231 cells that re-express ER $\alpha$

\section{Gene name}

\section{Affymetrix probe set} 201531_at 212442 s at 201339_s_at 218002_s_at 210517_s_at 209304_x_at

210059_s_at 211168_s_at 219480_at 205016_at 203058_s_at

205206_at 40829 at 218322_s_at

204158_s_at

200884_at 218532_s_at 205105_at 201720_s_at

205899_at 31637_s_at

203060_s_at

201721_s_at

218692 at 205009_at 210357_s_at 211429_s_at

220486_x_at 204326_x_at 202833_s_at

218749_s_at 203059_s_at

213004_at 217744_s_at 207935_s_at 212216_at 203071_at 202267_at 201131_s_at 202950 at 216323_x_at 203661 s at 202053_s_at

204368 at

209035 at 204664_at beta

synthase 2

member 5 transporting

cyclin A1

member 1

synthase 2 1 synthase 2

keratin 13

E-cadherin A2

midkine zinc finger protein 36

LAG1 longevity assurance homolog 6

sterol carrier protein 2

chemokine ligand 14

A kinase anchor protein 12

growth arrest and DNA damage-inducible,

mitogen-activated protein kinase 13

regulator of nonsense transcripts 1

snail homolog 1

transforming growth factor, alpha

3'-phosphoadenosine 5'-phosphosulfate

Kallmann syndrome 1 sequence

WD and tetratricopeptide repeats 1

acyl-CoA synthetase long-chain family

T-cell, immune regulator 1 , ATPase, $\mathrm{H}+$

creatine kinase

hypothetical protein FLJ20152

mannosidase, alpha $2 \mathrm{~A} 1$

Lysosomal-associated multispanning

membrane protein-5

nuclear receptor subfamily 1 , group $D$,

3'-phosphoadenosine $5^{\prime}$-phosphosulfate

Lysosomal-associated multispanning

membrane protein-5

hypothetical protein FLJ20366

trefoil factor 1

spermine oxidase

serine protease inhibitor, clade $A$, member

hypothetical protein FLJ22679

metallothionein $1 \mathrm{X}$

serine protease inhibitor, clade $A$, member

solute carrier family 24 , member 6

3'-phosphoadenosine $5^{\prime}$-phosphosulfate

angiopoietin-like 2

TP53 apoptosis effector

putative amino acid transporter

semaphorin 3B

laminin, gamma 2

crystallin, zeta

tubulin, alpha 2

tropomodulin 1

aldehyde dehydrogenase 3 family, member

solute carrier organic anion transporter family, member $2 \mathrm{~A} 1$

alkaline phosphatase
No. of EREs

Closest to consensus ERE sequence

3 GACCAnnnTGACT

LASS6

SCP2

CXCL14

AKAP12

GADD45B

GGACAnnnTGACT

AGGCAnnnTGACT

TCTCAnnnTGTCA

GGTCAnnnTGGTC (3)

MAPK13 3

RENT1 2

SNAI1 3

TGFA 4

PAPSS2 4

CGCCAnnnTGACC

GATCAnnnTGAAC

TGGCAnnnTGAGC

AGCCAnnnTGAGC

AGTCAnnnTGACC

KAL1

WDTC1 1

ACSL5 4

TGTCAnnnTGAAG GTTCAnnnTGACA GATCAnnnTGAAC

TCIRG1 6

GGTCAnnnTGACA

CKB

FLJ20152 3

MAN2A1 2

LAPTM5 3

CCNA1 1

NR1D1 4

PAPSS2 4

LAPTM5 3

GGGCAnnnTGAGG

TGTCAnnnTGCCC

AATCAnnnTGACC

GGGCAnnnTGACC

TTTCAnnnTGAAC

AGTCAnnnTGACT

AGTCAnnnTGACC

FLJ20366 4

TFF1 2

SMOX 4

SERPINA1 2

GGGCAnnnTGACC

FLJ22679

MT1X

1
4

SERPINA1 2

GTTCAnnnTGAAG

GGTCAnnnTGGCC

GACCAnnnTGACC

GGGCAnnnTGACT

$\begin{array}{ll}\text { SLC24A6 } & 6 \\ \text { PAPSS2 } & 4\end{array}$

ACTCAnnnTGAGT

CGACAnnnTGACA

GGGCAnnnTGACT

TGTCAnnnTGCCC AGTCAnnnTGACC

ANGPTL2 1

PERP 4

KRT13

KIAA0436

SEMA3B

LAMC2

$\mathrm{CDH} 1$

CRYZ

TUBA2

TMOD1

ALDH3A2

SLCO2A1

GATGAnnnTGAGG

GGTCAnnnTGGTC

TGTCAnnnTGACT

no sequence information available

3 GTGCAnnnTGACC

GGTCAnnnTGCCA

GGCCAnnnTGATG

AGCCAnnnTGAAG

?

CATCAnnnTGATC

TGCCAnnnTGACC

GATCAnnnTGAGG

MDK 2

ALPP 4
TCTCAnnnTGACA

GGTCAnnnTGGCA 
Table 3 Continued

\section{Gene name}

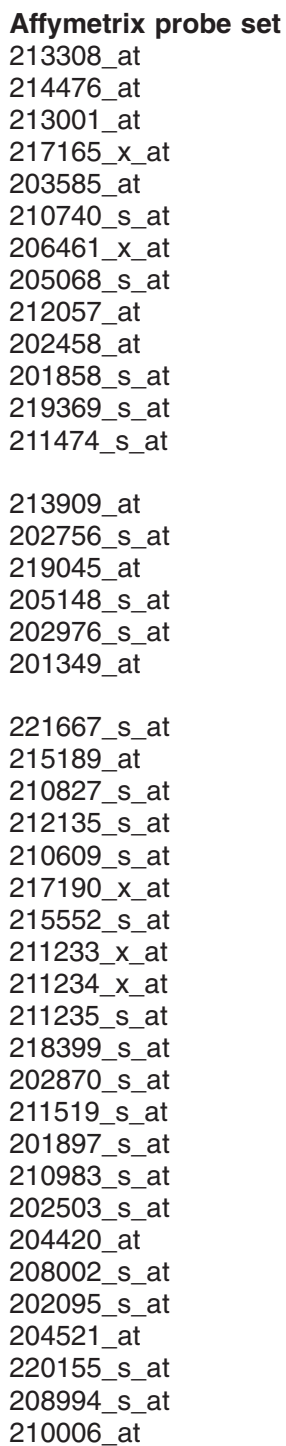
6

glypican 1 1

keratin 6

survivin
SH3 and multiple ankyrin repeat domains 2 trefoil factor 2

angiopoietin-like 2

metallothionein $2 \mathrm{~A}$

zinc finger protein 185

inositol 1,3,4-triphosphate 5/6 kinase

metallothionein $1 \mathrm{H}$

Rho GTPase activating protein 26

KIAA0182 protein

serine protease 23

proteoglycan 1

OUT domain, ubiquitin aldehyde binding 2

serine protease inhibitor, clade $B$, member

leucine rich repeat containing 15

ras homolog gene family, member 5

chloride channel 4

Rho-related BTB domain containing 3

solute carrier family 9 , isoform 3 regulator

heat shock protein 8

E74-like factor 3

ATPase, $\mathrm{Ca}++$ transporting

tumor protein $\mathrm{p} 53$ inducible protein 3

estrogen receptor alpha

estrogen receptor alpha

estrogen receptor alpha

estrogen receptor alpha

estrogen receptor alpha

cell division cycle associated 4

cell division cycle 20 homolog

kinesin family member $2 \mathrm{C}$

CDC28 protein kinase subunit 1B

minichromosome maintenance deficient 7

KIAA0101 gene product

FOS-like antigen 1

acyl-CoA hydrolase

predicted protein clone 23733

bromodomain containing 9

peptidyl-prolyl isomerase $\mathrm{G}$

DKFZP564O243 protein

Closest to consensus ERE sequence

No. of EREs

SHANK2
TFF2
ANGPTL2
MT2A
ZNF185
ITPK1
MT1H
ARHGAP26
KIAA0182
SPUVE
PRG1
OTUB2
SERPINB6

LRRC15
GPC1
RHOF
CLCN4
RHOBTB3
SLC9A3R1

HSPB8

KRTHB6

ELF3 6

ATP2B4 3

TP53।3

ESR1

ESR1

ESR1

ESR1

ESR1

CDCA4

CDC20

KIF2C

CKS1B

MCM7

KIAA0101

FOSL1

$\mathrm{BACH}$

BIRC5

HSU79724

BRD9

PPIG

DKFZP564O243
GGTCAnnnTCAGC

AGTCAnnnTGGCC

GATGAnnnTGAGG

TTTCAnnnTGAAA

GGTCAnnnTGACT

GGTCAnnnTGGCC

GTTCAnnnTGGCA

GCTCAnnnTGGGC

no sequence information available

1 AATCAnnnTGTTC

AGTCAnnnTGAGC

AGTCAnnnTGCCT

AGTGAnnnTGAGC

no sequence information available

1 GGTCAnnnTGAGG

TGACAnnnTGAGC

AGACAnnnTGAGA

GGTCAnnnTCACT

GCCCAnnnTGAGG

GGACAnnnTGAGA

GGCCAnnnTGACC

GACCAnnnTGAGC

ACTCAnnnTGTCT

TGTCAnnnTGAGA

AGTCAnnnTGAGA

AGTCAnnnTGAGA

AGTCAnnnTGAGA

AGTCAnnnTGAGA

AGTCAnnnTGAGA

AATCAnnnTGACC

GTTCAnnnTGATT

GTACAnnnTGACC

TGTCAnnnTGCCA

AGGCAnnnTGACT

GGTCAnnnTGGTC

GATCAnnnTGCCT

TTTCAnnnTGAGC

GGACAnnnTGATT

GCCCAnnnTGACC

GAGCAnnnTGACA

GACCAnnnTGACC

CGTCAnnnTGCCT

Putative EREs within $3000 \mathrm{bp}$ upstream from the transcriptional start site of each gene were identified by comparison to the consensus ERE (GGTCAnnnTGACC) allowing for a maximum of 2 base changes in either half-site. The total number of EREs found within the 3000 bp region is also indicated. Promoter sequences for genes associated with each Affymetrix probe set were extracted from the UCSC mouse genome browser via the NetAffx database (Liu et al. 2003).

phase (Reed 2003) and (4) SURVIVIN, is a member of the inhibitor of apoptosis (IAP) family that is involved in the regulation of cell division (Kobayashi et al. 1999). Importantly, the repression of these genes by E2 is consistent with the suppression of proliferation observed in E2-treated MDA-MB-231 cells that re-express ER $\alpha$ (Fig. 3). We speculate, therefore, that these transcriptional responses are associated directly with the anti-proliferative effects of E2 observed in these cells.

In order to identify additional E2-responsive regulators of cell proliferation and survival that may have been missed by our initial stringent ANOVA analysis, in which multi-testing correction was employed to minimise the false discovery rate (Fig. 4), we re-interrogated our transcript profiling data. We found 34 additional 
Table 4 Transcriptional responses associated with cell proliferation and survival in E2 stimulated MDA-MB-231 cells that re-express $\mathrm{ER} \alpha$

\section{Gene name}

\section{Affymetrix probe set} 205899_at

201621_at

219534_x_at

217744_s_at

213348_at

210538_s_at

209304_x_at

201482_at

222036_s_at

210559_s_at

204092_s_at

213677_s_at

209642 at

205394_at

204768 s at

202107_s_at

218399 s at

218355_at

202705 at

211519_s_at

203213 at

202870_s_at

218009_s_at

202095_s_at

201112_s_at

214710_s_at

201897_s_at

209773 s at

217786_at

201291_s_at

212563 at

210983_s_at

208795_s_at

208796 s at

(CDK1)

cyclin B2

(CDK1)

cytokinesis

1-like

cyclin B

\begin{tabular}{|c|c|c|c|}
\hline \multicolumn{2}{|l|}{ Gene name } & process & (mednIs.D.) \\
\hline cyclin A1 & CCNA1 & cell cycle & $6 \cdot 0 \pm 3 \cdot 0$ \\
\hline neuroblastoma & NBL1 & cell cycle & $5 \cdot 1 \pm 2 \cdot 8$ \\
\hline $\begin{array}{l}\text { suppression of } \\
\text { tumorigenicity } 1\end{array}$ & & & \\
\hline $\begin{array}{l}\text { cyclin-dependent kinase } \\
\text { inhibitor } 1 \mathrm{C}(\mathrm{p} 57, \mathrm{Kip} 2)\end{array}$ & CDKN1C & cell cycle & $3 \cdot 9 \pm 3 \cdot 1$ \\
\hline TP53 apoptosis effector & PERP & apoptosis & $2 \cdot 9 \pm 1 \cdot 2$ \\
\hline $\begin{array}{l}\text { cyclin-dependent kinase } \\
\text { inhibitor } 1 \mathrm{C}(\mathrm{p} 57, \mathrm{Kip} 2)\end{array}$ & CDKN1C & cell cycle & $2 \cdot 3 \pm 1 \cdot 0$ \\
\hline $\begin{array}{l}\text { baculoviral IAP } \\
\text { repeat-containing } 3\end{array}$ & BIRC3 & apoptosis & $3 \cdot 1 \pm 1 \cdot 9$ \\
\hline growth arrest and DNA & GADD45B & cell cycle/apoptosis & $4 \cdot 1 \pm 1 \cdot 5$ \\
\hline damage-inducible, beta & & & \\
\hline quiescin Q6 & QSCN6 & cell cycle/cell proliferation & $2.2 \pm 0.9$ \\
\hline minichromosome & MCM4 & DNA replication & $0 \cdot 7 \pm 0.4$ \\
\hline $\begin{array}{l}\text { cell division cycle } 2 \\
\text { (CDK1) }\end{array}$ & CDC2 & cell cycle & $0.5 \pm 0.08$ \\
\hline serine/threonine kinase 6 & STK6 & cell cycle & $0.7 \pm 0.2$ \\
\hline $\begin{array}{l}\text { postmeiotic segregation } \\
\text { increased } 1\end{array}$ & PMS1 & cell cycle & $0.8 \pm 0.02$ \\
\hline $\begin{array}{l}\text { budding inhibited by } \\
\text { benzimidazoles } 1 \text { homolog }\end{array}$ & BUB1 & cell cycle & $0.6 \pm 0.07$ \\
\hline CHK1 checkpoint homolog & CHEK1 & cell cycle/cell proliferation & $0.7 \pm 0.07$ \\
\hline $\begin{array}{l}\text { flap structure-specific } \\
\text { endonuclease } 1\end{array}$ & FEN1 & DNA replication & $0.8 \pm 0.1$ \\
\hline minichromosome & MCM2 & DNA replication/cell cycle & $0.7 \pm 0.05$ \\
\hline $\begin{array}{l}\text { cell division cycle } \\
\text { associated } 4\end{array}$ & CDCA4 & cell cycle & $0.6 \pm 0.09$ \\
\hline kinesin family member $4 \mathrm{~A}$ & KIF4A & cell cycle & $0.5 \pm 0.09$ \\
\hline cyclin B2 & CCNB2 & cell cycle & $0.6 \pm 0.05$ \\
\hline kinesin family member $2 \mathrm{C}$ & KIF2C & cell cycle & $0.5 \pm 0.1$ \\
\hline $\begin{array}{l}\text { cell division cycle } 2 \\
\text { (CDK1) }\end{array}$ & CDC2 & cell cycle & $0.5 \pm 0.2$ \\
\hline $\begin{array}{l}\text { cell division cycle } 20 \\
\text { homolog }\end{array}$ & CDC20 & cell cycle & $0.5 \pm 0.1$ \\
\hline $\begin{array}{l}\text { protein regulator of } \\
\text { cytokinesis }\end{array}$ & PRC1 & cell cycle & $0.5 \pm 0.1$ \\
\hline $\begin{array}{l}\text { baculoviral IAP } \\
\text { repeat-containing } 5 \\
\text { (survivin) }\end{array}$ & BIRC5 & cell cycle/apoptosis & $0.5 \pm 0.06$ \\
\hline $\begin{array}{l}\text { chromosome segregation } \\
\text { 1-like }\end{array}$ & CSE1L & cell proliferation/apoptosis & $0.7 \pm 0.1$ \\
\hline cyclin B1 & CCNB1 & cell cycle & $0.5 \pm 0.07$ \\
\hline $\begin{array}{l}\text { CDC28 protein kinase } \\
\text { regulatory subunit } 1 \mathrm{~B}\end{array}$ & CKS1B & cell proliferation & $0.6 \pm 0.1$ \\
\hline $\begin{array}{l}\text { ribonucleotide reductase } \\
\text { M2 polypeptide }\end{array}$ & RRM2 & DNA replication & $0.5 \pm 0.07$ \\
\hline SKB1 homolog & SKB1 & cell cycle/cell proliferation & $0.7 \pm 0.1$ \\
\hline $\begin{array}{l}\text { DNA topoisomerase II } \\
\text { alpha }\end{array}$ & TOP2A & DNA replication & $0.5 \pm 0.2$ \\
\hline block of proliferation 1 & BOP1 & cell proliferation & $0.6 \pm 0.03$ \\
\hline $\begin{array}{l}\text { minichromosome } \\
\text { maintenance deficient } 7\end{array}$ & MCM7 & DNA replication/cell cycle & $0.5 \pm 0.1$ \\
\hline $\begin{array}{l}\text { minichromosome } \\
\text { maintenance deficient } 7\end{array}$ & MCM7 & DNA replication/cell cycle & $0.5 \pm 0.1$ \\
\hline cyclin G1 & CCNG1 & cell cycle & $0.7 \pm 0.2$ \\
\hline
\end{tabular}

Biological pathway/ process

cell cycle

suppression of

cyclin-dependent kinase

inhibitor 1C (p57, Kip2)

TP53 apoptosis effector

clin-dependent kinase

baculoviral IAP

repeat-containing 3

growth arrest and DNA

(amage-inducible, beta

minichromosome

cell division cycle 2

budding inhibited by

flap structure-specific

maintenance deficient 2

cellivision cycle

kinesin family member $4 \mathrm{~A}$

cell division cycle 20

repeat-containing 5

ribonucleotide reductase

M2 polypeptide

SKB1 homolog

A topoisomerase

block of proliferation 1

maintenance deficient 7

maintenance deficient 7
Ratio of gene

expression E2:AO

(mean士S.D.)

$5 \cdot 1 \pm 2 \cdot 8$

$3 \cdot 9 \pm 3 \cdot 1$

$9 \pm 1 \cdot 2$

$3 \cdot 1 \pm 1 \cdot 9$

$4 \cdot 1 \pm 1 \cdot 5$

$2 \cdot 2 \pm 0.9$

$0.5 \pm 0.08$

$0.7 \pm 0.2$

$0.6 \pm 0.07$

$0.7 \pm 0.07$

$0.6 \pm 0.09$

$0.6 \pm 0.05$

$0.5 \pm 0.1$

$0.5 \pm 0$.

$0.5 \pm 0.1$

$0.5 \pm 0.06$

$0.5 \pm 0.07$

$0.7 \pm 0.1$

$0.5 \pm 0.2$

$0.6 \pm 0.03$

$0.5 \pm 0.1$

$0 \cdot 7 \pm 0 \cdot 2$ 
Table 4 Continued

\section{Gene name}

Affymetrix probe se
200920 s_at
204240 s_at
210766 s_at
201555 at
219350 s_at
211036 _at
201457 x_at
208021 s_at

B-cell translocaiton gene 1 structural maintenance of chromosomes 2-like 1 chromosome segregation 1-like

minichromosome maintenance deficient 3 diable homolog anaphase promoting complex subnit 5 budding inhibited by benzimidazoles 3 homolog replication factor $\mathrm{C} 1$

\section{Biological pathway/ process}

BTG1 cell cycle/cell proliferation/apoptosis

SMC2L1

CSE1L

MCM3

DIABLO

ANAPC5

BUB3

RFC1 cell cycle

cell proliferation/apoptosis

DNA replication/cell cycle

apoptosis

cell cycle

cell cycle

DNA replication
Ratio of gene expression E2:AO (mean \pm S.D.)

$0.7 \pm 0.09$

$0.6 \pm 0.05$

$0.9 \pm 0.3$

$0 \cdot 8 \pm 0 \cdot 2$

$0 \cdot 7 \pm 0.06$

$0.8 \pm 0.08$

$0 \cdot 8 \pm 0 \cdot 07$

$0.6 \pm 0.04$

Gene ontology classifications for DNA replication, cell cycle, cell proliferation and cell survival were used to interrogate 574 genes exhibiting a significant (students t-test $\mathrm{P}<0.05$ ) alteration in their expression due to estrogen stimulation. Mean gene expression ratios \pm S.D. (E2-treated relative to vehicle control; based on 3 independent biological replicate experiments) are shown together with Affymetrix GeneChip probe set, gene name, biological pathway/process (as of the NetAffx update on 23 June 2004). Two or more Affymetrix GeneChip probe sets for the same gene indicates that probe sets specific for independent regions of the same gene demonstrated estrogen-regulated expression.

E2-responsive probe sets (Student's $t$-test $P<0 \cdot 05)$ whose gene ontology classifications were consistent with a role in the regulation of cell cycle progression, proliferation or survival (Table 4). This analysis revealed that E2 down-regulated the expression of many additional genes involved in cell cycle progression $(C D C 2, C T C L I N$ N $B 1$, CYCLIN B2, CYCLIN G1, CHK1, BUB3, STK6, SKB1, CSE1) and chromosome replication (MCM2, MCM3, FEN1, RRM2, TOPII, RFC1). A number of negative regulators of the cell cycle were also induced by E2, including KIP2, NBL1 (neuroblastoma suppressor of tumorigenicity 1, also known as DAN; Ozaki et al. 1995) and QUIESCIN Q6 (Coppock et al. 1998). The functional relationships between the numerous estrogen-responsive cell cycle regulators identified in this study (Table 4) are summarised in the cell cycle pathway map shown in Fig. 5. The overall effect of changes in the expression of these cell cycle genes is consistent with the observed suppression of proliferation (Fig. 3).

Opposing estrogen-dependent transcriptional regulation of cell cycle genes in MDA-MB-231 cells that re-express ERa and ERa-positive MCF-7 breast cancer cells

Further evidence for the involvement of the genes described above in the suppression of proliferation in our model system is provided by previous reports showing that the expression of many of the same genes is regulated in the opposite direction in ER-positive MCF-7 breast cancer cells treated with E2 (Table 5). Transcript profiling previously revealed that FEN1, MCM2, MCM3, MCM7, CDC2, CDC20, BUB1, STK6,
CSE1 $L$ and SURVIVIN are up-regulated during E2-induced proliferation of MCF-7 cells (Lobenhofer et al. 2002, Frasor et al. 2003). This is in contrast to the repression of these genes by E2 in MDA-MB-231 cells that re-express $\mathrm{ER} \alpha$ in the microarray analysis reported here (Table 5). Quantitative real-time PCR analysis of the E2-responsiveness of these genes in both MCF-7 cells and MDA-MB-231 cells that re-express ER $\alpha$ confirms and extends our observations of opposing transcriptional responses to E2 in these two cell types (Fig. 6). We conclude that the paradoxical antiproliferative effects of E2 in MDA-MB-231 cells that overexpress ER $\alpha$ may be due to the aberrant regulation of key cell cycle regulators.

\section{Opposing estrogen-dependent transcriptional regulation of growth-related genes in MDA-MB-231 cells that re-express ERa and ERa-positive MCF-7 breast cancer cells}

In addition to the aberrant regulation of cell cycle genes, we also found that a number of growth-related genes were regulated by $\mathrm{E} 2$ in the opposite direction in ER-negative MDA-MB-231 cells that re-express ER $\alpha$ compared with ER-positive MCF7 cells. These include E-CADHERIN (CDH1), an important mediator of cell-cell interactions that acts as a tumour suppressor gene and whose loss of expression is associated with invasive growth (Thiery 2002). CDH1 is down-regulated by E2 in ER-containing breast cancer cells (Oesterreich et al. 2003), but is up-regulated in MDA-MD-231 cells transfected with ER $\alpha$ (Table 5). This suggests that the negative growth response to E2 in these cells may 


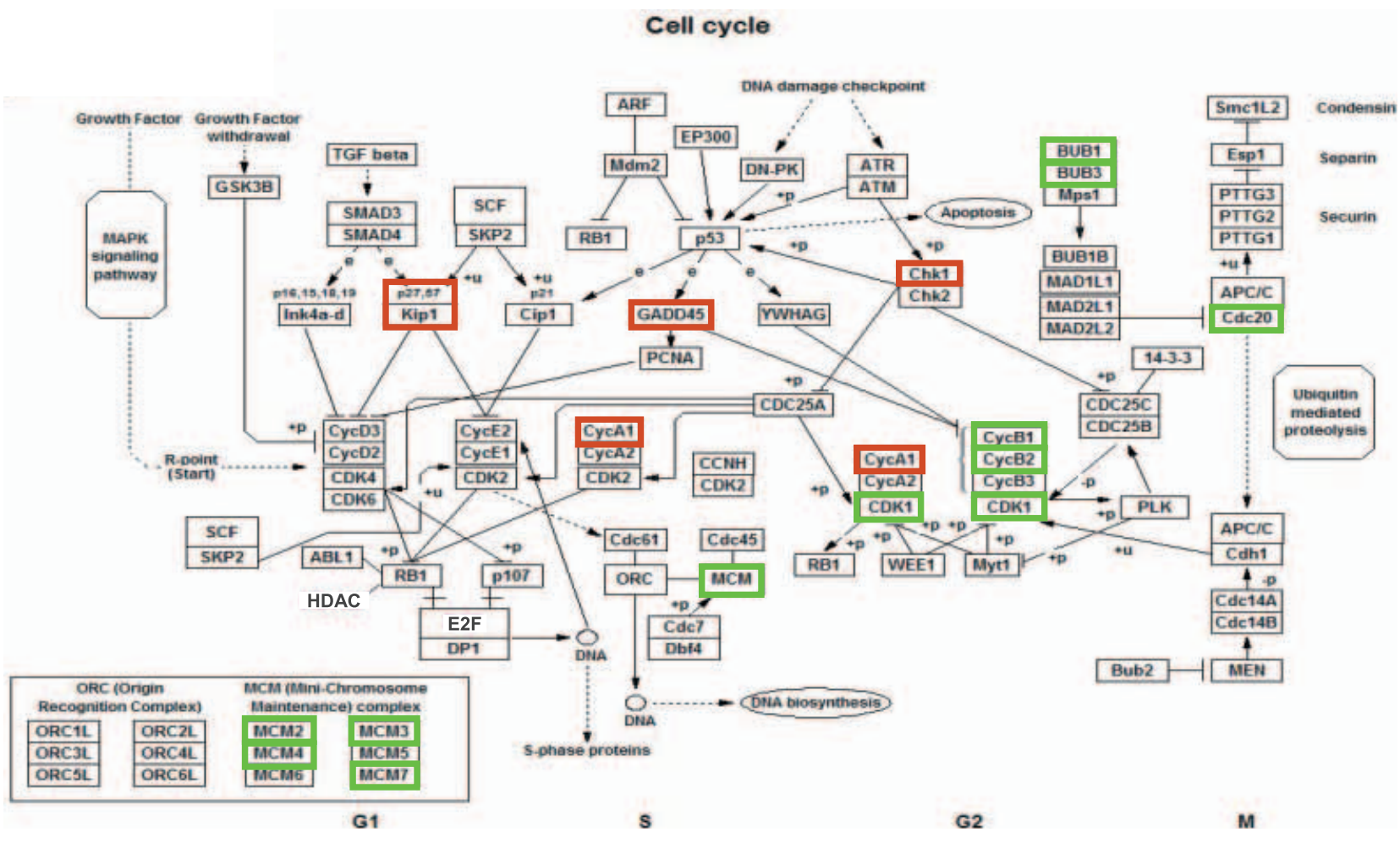

Figure 5 E2-responsive cell cycle genes in MDA-MB-231 cells that re-express ER $\alpha$. The cell cycle pathway map was originally adapted from KEGG and was obtained from www.GenMAPP.org (Dahlquist et al. 2002). Red and green boxes indicate up- and down-regulation of gene expression by estrogen, respectively.

involve alteration of epithelial cell architecture. Surprisingly, the SNAIL gene, a known negative transcriptional regulator of $\mathrm{CDH} 1$, was also up-regulated by $\mathrm{E} 2$ in these cells (Table 2), an event that is normally associated with the loss of expression of CDH1 (Fujita et al. 2003). Nevertheless, our data reveal the altered expression in these cells by E2 of two genes associated with the invasive growth pathway in breast cancer.

Components of the c-myc and AP-1 transcription factors also show opposing transcriptional responses in breast cancer cells containing endogenous versus transfected ER $\alpha$. The gene encoding the AP-1 transcription factor, Fos-like antigen 1 (FOSL1; also known as FRA-1), is repressed by E2 in MDA-MB-231 cells transfected with ER $\alpha$ (Table 2, Fig. 6), consistent with previous observations that AP-1 activity is inhibited by E2 in MDA-MB-231 cells stably transfected with ERa (Philips et al. 1998). Furthermore, c-myc has previously been reported to be repressed by E2 in MDA-MB-231 cells transfected with adenovirally encoded ER $\alpha$ (Lazennec \& Katzenellenbogen 1999). The repression of these genes by E2 in cells that re-express $\mathrm{ER} \alpha$ is in marked contrast to their induction by $\mathrm{E} 2$ in MCF-7 cells (Fig. 6; van der Burg et al. 1989, Weisz et al. 1990) and suggests that the negative regulation of transcription factors that control growth and differentia- tion may be a key event leading to the E2-dependent suppression of proliferation in MDA-MB-231 cells that re-express ER $\alpha$.

Overall, these data reveal the diverse gene networks and metabolic and cell regulatory pathways through which E2 exerts its effects on MDA-MB-231 breast cancer cells that re-express ER $\alpha$, and provide novel mechanistic insights into the anti-proliferative effect of E2 in these cells.

\section{Discussion}

We have used gene expression profiling to obtain a holistic view of the transcriptional responses associated with the effects of estrogen in ER-negative MDA-MB231 breast cancer cells that re-express ER $\alpha$. The genes we have identified are likely to be regulated directly by E2. Evidence for this comes from: (1) the dependence of their regulation on E2; (2) the requirement for ER $\alpha$ and (3) the presence of consensus EREs within $3000 \mathrm{bp}$ upstream of their transcriptional start sites. Moreover, the molecular functions of many of the E2-responsive genes that we have identified, including chromosome replication, cell cycle regulation, cell survival and growth factor signalling, provide novel insights into the mechanisms underlying the E2-induced suppression of 
Table 5 Opposing transcriptional responses to E2 in ER-positive MCF-7 cells versus MDA-MB-231 cells that re-express ER $\alpha$

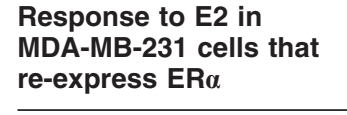

\section{Gene name}

cell division cycle 20 homolog

cell division cycle 2 (CDK1)

CDC28 protein kinase regulatory subunit $1 \mathrm{~B}$

budding inhibited by benzimidazoles 1 homolog minichromosome maintenance deficient 2 minichromosome maintenance deficient 3

minichromosome maintenance deficient 7 flap structure-specific endonuclease 1 replication factor $\mathrm{C} 1$

chromosome segregation 1-like serine/threonine kinase 6

baculoviral IAP repeat-containing 5 (survivin) E-cadherin

\section{Response to E2 \\ in ER-positive \\ MCF-7 cells}

\begin{tabular}{|c|c|c|}
\hline CDC20 & down-regulated ${ }^{1}$ & $\begin{array}{l}\text { up-regulated (Lobenhofer et al. } 2002 \text { Frasor et al. } \\
\text { 2003) }\end{array}$ \\
\hline CDC2 & down-regulated ${ }^{1}$ & up-regulated (Frasor et al. 2003) \\
\hline CKS1B & down-regulated ${ }^{1}$ & $\begin{array}{l}\text { up-regulation of CDC28 protein kinase } 2 \\
\text { (Lobenhofer et al. 2002) }\end{array}$ \\
\hline BUB1 & down-regulated ${ }^{1}$ & up-regulated (Frasor et al. 2003) \\
\hline MCM2 & down-regulated ${ }^{1}$ & up-regulated (Frasor et al. 2003) \\
\hline МСM3 & down-regulated ${ }^{1}$ & $\begin{array}{l}\text { up-regulated (Lobenhofer et al. 2002; Frasor et al. } \\
\text { 2003) }\end{array}$ \\
\hline MCM7 & down-regulated ${ }^{1}$ & up-regulated (Lobenhofer et al. 2002) \\
\hline FEN1 & down-regulated ${ }^{1}$ & up-regulated (Lobenhofer et al. 2002) \\
\hline RFC1 & down-regulated ${ }^{1}$ & $\begin{array}{l}\text { up-regulation of RFC3 (Lobenhofer et al. 2002) } \\
\text { and RFC4 (Frasor et al. 2003) }\end{array}$ \\
\hline CSE1L & down-regulated ${ }^{1}$ & up-regulated (Lobenhofer et al. 2002) \\
\hline STK6 & down-regulated ${ }^{1}$ & up-regulated (Frasor et al. 2003) \\
\hline BIRC5 & down-regulated ${ }^{1}$ & up-regulated (Frasor et al. 2003) \\
\hline $\mathrm{CDH} 1$ & up-regulated ${ }^{1}$ & down-regulated (Osterreich et al. 2003) \\
\hline
\end{tabular}

${ }^{1}$ Quantitative gene expression data are shown in Table 4.

proliferation in ER-negative breast cancer cells that re-express ERa (Garcia et al. 1992, Levenson \& Jordan 1994). Importantly, our data reveal that several key regulators of cell proliferation and survival are regulated in opposite directions when compared with their behaviour in ER-positive MCF-7 breast cancer cells. Therefore, these data go some way towards explaining the paradoxical effects of estrogens in ER-negative breast cancer cells in which $\mathrm{ER} \alpha$ has been re-expressed.

An important question arising from our studies is how E2-bound $\mathrm{ER} \alpha$ targets the same genes with opposing transcriptional outcomes in ER-negative and ERpositive breast cancer cells. Transfection of functional $\mathrm{ER} \alpha$ into MDA-MB-231 cells does not alter gene expression significantly in the absence of exogenous E2 (Fig. 4; Lazennec \& Katzenellenbogen 1999), indicating that re-expression of $\operatorname{ER} \alpha$ per se does not alter the transcriptional status of these genes. Since ER-mediated transcriptional regulation involves a plethora of coregulator proteins (Moggs \& Orphanides 2001, Hall et al. 2001, McKenna \& O’Malley 2002, Tremblay \& Giguere 2002), it is possible that cell type-specific differences in transcriptional responses to estrogens are due to differences in the expression levels, accessibility, or localisation of critical cofactors. Precedent exists for this mechanism: higher levels of steroid receptor coactivator 1 (SRC-1) expression in Ishikawa endometrial cells, compared with MCF-7 breast cancer cells, result in opposing cellular responses to the selective estrogen receptor modulator tamoxifen (Shang \& Brown 2002). Furthermore, the altered localisation of Retinoid $\times$ receptor alpha $(\mathrm{RXR} \alpha)$ in MDA-MB-231 cells versus MCF-7 cells has been associated with the differential responsiveness of these cell lines to retinoids (Tanaka et al. 2004). RXR $\alpha$ is localized throughout the nucleoplasm in the retinoid-responsive MCF-7 breast cancer cell line, whereas it is found in the splicing factor compartment of the retinoid-resistant MDA-MB-231 breast cancer cell line. Interestingly, previous studies have shown that hydroxytamoxifen can reverse the suppression of proliferation by E2 in MDA-MB-231 cells that re-express $\operatorname{ER} \alpha$ (Garcia et al. 1992, Lazennec \& Katzenellenbogen 1999). Since hydroxytamoxifen normally suppresses proliferation in ER-containing breast cancer cells, these observations are consistent with MDA-MB-231 cells lacking the full complement of cofactors that are required for appropriate regulation of proliferation by E2 and anti-estrogens.

Another factor that may contribute to the contrasting ER-mediated transcriptional effects seen in MDA-MB231 and MCF-7 cells is the DNA methylation status and chromatin structure of the gene regulatory regions. Indeed, DNA methylation status determines the expression levels of $\mathrm{ER} \alpha$ in breast cancer cells: silencing of the ER $\alpha$ gene in MDA-MB-231 cells occurs through epigenetic alterations that include the hypermethylation of $\mathrm{CpG}$ island DNA sequences in the gene promoter region (Ottaviano et al. 1994). Consistent with the existence of an epigenetic silencing mechanism in MDA-MB-231 cells, the ER $\alpha$ gene can be reactivated by the DNA methyltransferase inhibitor, 5-aza-2'deoxycytidine (Ferguson et al. 1995), and the histone deacetylase inhibitor, trichostatin A (Yang et al. 2000), and a combination of these inhibitors results in the 


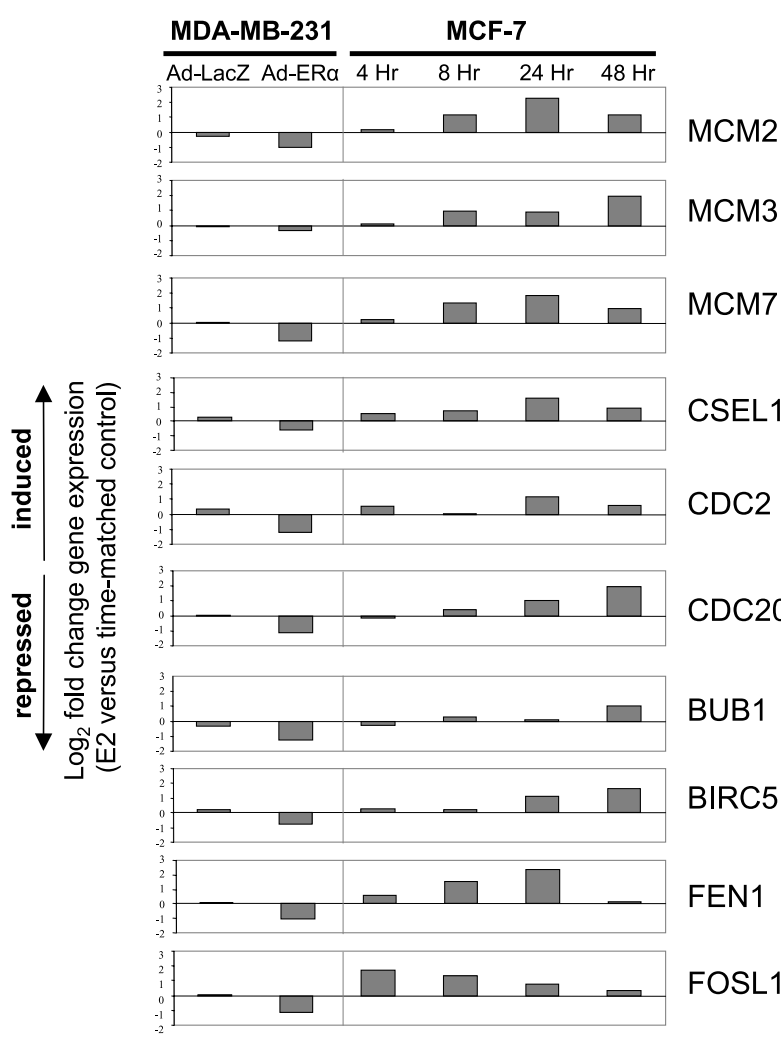

Figure 6 Quantitative real-time PCR analysis of opposing transcriptional responses in MCF-7 versus MDA-MD-231 breast cancer cells that re-express ER $\alpha$. MDA-MB-231 cells were transfected with either Ad-LacZ or Ad-ER $\alpha$ before treatment with either vehicle control $\left(0.01 \%\right.$ ethanol) or $10^{-8} \mathrm{M}$ E2 for $48 \mathrm{~h}$. MCF-7 cells were treated with either vehicle control $\left(0.1 \%\right.$ ethanol) or $10^{-9} \mathrm{M} \mathrm{E2}$ for $4,8,24$ and $48 \mathrm{~h}$. E2-dependent changes in gene expression are shown relative to time-matched vehicle controls. $\Delta \Delta \mathrm{Ct}$ was calculated by normalising to the control gene RPLP0/36B4 (Accession number: NM_001002; Laborda 1991) and comparative Ct values are shown as $\log _{2}$ fold changes.

synergistic reactivation of $\mathrm{ER} \alpha$ (Yang et al. 2001). It is, therefore, likely that differences in the direction of E2-induced gene regulation between MDA-MB-231 and MCF-7 cells may be due to differences in the epigenetic status of target genes.

The poor prognosis of ER-negative breast cancers, together with their unresponsiveness to anti-estrogen therapy, creates an urgent need for novel targeted therapies that do not rely on inhibition of ERa (Rochefort et al. 2003). Alternative approaches have met with some success. For example, over-expression of the human epidermal growth fator-2 (HER2) oncogene in human breast cancers has been associated with a more aggressive progression of disease, and a monoclonal antibody (trastuzumab) directed against the extracellular domain of HER2 is therapeutically active in a proportion of HER2-positive breast tumours (Menard et al. 2003). We have identified the transcriptional networks through which ER $\alpha$ is able to inhibit the proliferation of an ER-negative cell line. Targeting of these, or similar, pathways may lead to the development of novel approaches for the control of ER-negative breast tumours.

\section{Acknowledgements}

We would like to thank $\mathrm{K}$ Bundell (AstraZeneca Pharmaceuticals, Macclesfield, UK) for the generous gift of adenovirus DNA constructs for the expression of LacZ and human ER $\alpha$ and also J Edmunds for generating the MCF-7 cell RNA samples. We would also like to thank $\mathrm{T}$ Barlow and B Jeffery from the Food Standards Agency and our colleagues at Syngenta CTL for their guidance and advice throughout the course of this project. This work was partially supported by a grant from the UK Food Standards Agency. The authors declare that they have no conflict of interest.

\section{References}

Bard JB \& Rhee SY 2004 Ontologies in biology: design, applications and future challenges. Nature Reviews Genetics 5 213-222.

Benjamini Y \& Hochberg Y 1995 Controlling the False Discovery Rate: a Practical and Powerful Approach to Multiple Testing. Fournal of the Royal Statistical Society: Series B 57 289-300.

Berry M, Nunez AM \& Chambon P 1989 Estrogen-responsive element of the human $\mathrm{pS} 2$ gene is an imperfectly palindromic sequence. PNAS 86 1218-1222.

Blow JJ \& Hodgson B 2002 Replication licensing - defining the proliferative state? Trends in Cell Biology 12 72-78.

Bourdeau V, Deschenes J, Metivier R, Nagai Y, Nguyen D, Bretschneider N, Gannon F, White JH \& Mader S 2004 Genome-wide identification of high-affinity estrogen response elements in human and mouse. Molecular Endocrinology 18 1411-1427.

Coppock DL, Cina-Poppe D \& Gilleran S 1998 The quiescin Q6 gene (QSCN6) is a fusion of two ancient gene families: thioredoxin and ERV1. Genomics 54 460-468.

van der Burg B, van Selm-Miltenburg AJ, de Laat SW \& van Zoelen EJ 1989 Direct effects of estrogen on c-fos and c-myc protooncogene expression and cellular proliferation in human breast cancer cells. Molecular and Cellular Endocrinology 64 223-228.

Dahlquist KD, Salomonis N, Vranizan K, Lawlor SC \& Conklin BR 2002 GenMAPP, a new tool for viewing and analyzing microarray data on biological pathways. Nature Genetics 31 19-20.

Davidson NE, Bronzert DA, Chambon P, Gelmann EP \& Lippman ME 1986 Use of two MCF-7 cell variants to evaluate the growth regulatory potential of estrogen-induced products. Cancer Research 46 1904-1908.

Ferguson AT, Lapidus RG, Baylin SB \& Davidson NE 1995 Demethylation of the estrogen receptor gene in estrogen receptor-negative breast cancer cells can reactivate estrogen receptor gene expression. Cancer Research 55 2279-2283

Frasor J, Danes JM, Komm B, Chang KC, Lyttle CR \& Katzenellenbogen BS 2003 Profiling of estrogen up- and down-regulated gene expression in human breast cancer cells: insights into gene networks and pathways underlying estrogenic 
control of proliferation and cell phenotype. Endocrinology 144 4562-4574.

Fujita N, Jaye DL, Kajita M, Geigerman C, Moreno CS \& Wade PA 2003 MTA3, a Mi-2/NuRD complex subunit, regulates an invasive growth pathway in breast cancer. Cell 113 207-219.

Garcia M, Derocq D, Freiss G \& Rochefort H 1992 Activation of estrogen receptor transfected into a receptor-negative breast cancer cell line decreases the metastatic and invasive potential of the cells. PNAS 89 11538-11542.

GEO 2004 Gene Expression Omnibus Homepage, Bethesda, MD: National Center for Biotechnology Information, National Library of Medicine, Available: http://wrwrencbi.nlm.nih.gov/geo/.

Green S, Walter P, Kumar V, Krust A, Bornert JM, Argos P \& Chambon P 1986 Human oestrogen receptor cDNA: sequence, expression and homology to v-erb-A. Nature 320 134-139.

Hall JM, Couse JF \& Korach KS 2001 The multifaceted mechanisms of estradiol and estrogen receptor signaling. Fournal of Biological Chemistry 276 36869-36872.

He TC, Zhou S, da Costa LT, Yu J, Kinzler KW \& Vogelstein B 1998 A simplified system for generating recombinant adenoviruses. PNAS 95 2509-2514.

Klinge CM 2001 Estrogen receptor interaction with estrogen response elements. Nucleic Acids Research 9 2905-2919.

Kobayashi K, Hatano M, Otaki M, Ogasawara T \& Tokuhisa T 1999 Expression of a murine homologue of the inhibitor of apoptosis protein is related to cell proliferation. PNAS 96 $1457-1462$.

Laborda J 1991 36B4 cDNA used as an estradiol-independent mRNA control is the cDNA for human acidic ribosomal phosphoprotein P0. Nucleic Acids Research 193998.

Lazennec G \& Katzenellenbogen BS 1999 Expression of human estrogen receptor using an efficient adenoviral gene delivery system is able to restore hormone-dependent features to estrogen receptor-negative breast carcinoma cells. Molecular and Cellular Endocrinology 149 93-105.

Levenson AS \& Jordan C 1994 Transfection of Human Estrogen Receptor (ER) cDNA into ER-negative Mammalian Cell Lines. Fournal of Steroid Biochemistry and Molecular Biology 51 229-239.

Levenson AS, Svoboda KM, Pease KM, Kaiser SA, Chen B, Simons LA, Jovanovic BD, Dyck PA \& Jordan VC 2002 Gene expression profiles with activation of the estrogen receptor alpha-selective estrogen receptor modulator complex in breast cancer cells expressing wild-type estrogen receptor. Cancer Research 62 4419-4426.

Liu G, Loraine AE, Shigeta R, Cline M, Cheng J, Valmeekam V, Sun S, Kulp D \& Siani-Rose MA 2003 NetAffx: Affymetrix probesets and annotations. Nucleic Acids Research $3182-86$

Lobenhofer EK, Bennett L, Cable PL, Li L, Bushel PR \& Afshari CA 2002 Regulation of DNA replication fork genes by 17 beta-estradiol. Molecular Endocrinology 16 1215-1229.

McKenna NJ \& O'Malley BW 2002 Combinatorial control of gene expression by nuclear receptors and coregulators. Cell $\mathbf{1 0 8}$ 465-474

Menard S, Pupa SM, Campiglio M \& Tagliabue E 2003 Biologic and therapeutic role of HER2 in cancer. Oncogene 22 6570-6578.

Moggs JG \& Orphanides G 2001 Estrogen receptors: orchestrators of pleiotropic cellular responses. EMBO Reports 2 775-781.

Murphy TC \& Orphanides G 2002 Characterisation of the molecular responses to xenoestrogens using gene expression profiling. Phytochemistry Reviews 1 199-208.

Oesterreich S, Deng W, Jiang S, Cui X, Ivanova M, Schiff R, Kang K, Hadsell DL, Behrens J \& Lee AV 2003 Estrogen-mediated
Down-regulation of E-cadherin in Breast Cancer Cells. Cancer Research 63 5203-5208.

Ottaviano YL, Issa JP, Parl FF, Smith HS, Baylin SB \& Davidson NE 1994 Methylation of the estrogen receptor gene CpG island marks loss of estrogen receptor expression in human breast cancer cells. Cancer Research 54 2552-2555.

Ozaki T, Nakamura Y, Enomoto H, Hirose M \& Sakiyama S 1995 Overexpression of DAN gene product in normal rat fibroblasts causes a retardation of the entry into the $\mathrm{S}$ phase. Cancer Research 55 895-900.

Philips A, Teyssier C, Galtier F, Rivier-Covas C, Rey JM, Rochefort H \& Chalbos D 1998 FRA-1 expression level modulates regulation of activator protein-1 activity by estradiol in breast cancer cells. Molecular Endocrinology 12 973-985.

Pike MC, Spicer DV, Dahmoush L \& Press MF 1993 Estrogens, progestogens, normal breast cell proliferation, and breast cancer risk. Epidemiologic Reviews 15 17-35.

Prall OW, Sarcevic B, Musgrove EA, Watts CK \& Sutherland RL 1997 Estrogen-induced activation of Cdk4 and Cdk2 during G1-S phase progression is accompanied by increased cyclin D1 expression and decreased cyclin-dependent kinase inhibitor association with cyclin E-Cdk2. Journal of Biological Chemistry 272 10882-10894.

Reed SI 2003 Ratchets and clocks: the cell cycle, ubiquitylation and protein turnover. Nature Reviews Molecular Cell Biology 4 855-864.

Rochefort H, Glondu M, Sahla ME, Platet N \& Garcia M 2003 How to target estrogen receptor-negative breast cancer? Endocrine Related Cancer 10 261-266.

Sambrook J, Fritsch EF \& Maniatis T 1989 Molecular Cloning: A Laboratory Manual, 2nd edition. Cold Spring Harbor, NY: Cold Spring Harbor Laboratory Press.

Shang Y \& Brown M 2002 Molecular determinants for the tissue specificity of SERMs. Science 295 2380-2381.

Tanaka T, Dancheck BL, Trifiletti LC, Birnkrant RE, Taylor BJ, Garfield SH, Thorgeirsson U \& De Luca LM 2004 Altered localization of retinoid $\mathrm{X}$ receptor alpha coincides with loss of retinoid responsiveness in human breast cancer MDA-MB-231 cells. Molecular and Cellular Biology 24 3972-3982.

Thiery JP 2002 Epithelial-mesenchymal transitions in tumour progression. Nature Reviews Cancer 2 442-454.

Tremblay GB \& Giguere V 2002 Coregulators of estrogen receptor action. Critical Reviews in Eukaryotic Gene Expression 12 1-22

Vodermaier HC 2001 Cell cycle: Waiters serving the Destruction machinery. Current Biology 11 R834-R837.

Vogel VG \& Lo S 2003 Preventing hormone-dependent breast cancer in high-risk women. Fournal of the National Cancer Institute $\mathbf{9 5}$ 91-93.

Weisz A, Cicatiello L, Persico E, Scalona M \& Bresciani F 1990 Estrogen stimulates transcription of c-jun protooncogene. Molecular Endocrinology 4 1041-1050.

Yang X, Ferguson AT, Nass SJ, Phillips DL, Butash KA, Wang SM, Herman JG \& Davidson NE 2000 Transcriptional activation of estrogen receptor alpha in human breast cancer cells by histone deacetylase inhibition. Cancer Research 60 6890-6894.

Yang X, Phillips DL, Ferguson AT, Nelson WG, Herman JG \& Davidson NE 2001 Synergistic activation of functional estrogen receptor (ER)-alpha by DNA methyltransferase and histone deacetylase inhibition in human ER-alpha-negative breast cancer cells. Cancer Research 61 7025-7029.

Received 22 November 2004 Accepted 13 December 2004 